\title{
Organizational Adaptability Influenced by Practice Strategy, Environmental Dynamism, and Absorptive Capacity
}

\author{
Yunhao Gong $\mathbb{D}$, Yun Le $\mathbb{D}$, Xinyue Zhang $\mathbb{D}$, Xiaoyan Chen $(\mathbb{D}$, and Hui Zeng \\ School of Economics and Management, Tongji University, Shanghai 200092, China \\ Correspondence should be addressed to Hui Zeng; 1910458@tongji.edu.cn
}

Received 9 October 2021; Revised 11 November 2021; Accepted 11 December 2021; Published 24 December 2021

Academic Editor: Hiroki Sayama

Copyright $\odot 2021$ Yunhao Gong et al. This is an open access article distributed under the Creative Commons Attribution License, which permits unrestricted use, distribution, and reproduction in any medium, provided the original work is properly cited.

\begin{abstract}
The adaptability of organizations to their environment has always been a key concern in both organizational theory and management practice. Different from the single perspective of previous studies, this research adopts an integrated, outside-in perspective. Employing an agent-based simulation model (ASM) and a multiple regression model (MRM), we examine the impact of the intensity of exploitative and exploratory practice on organizational adaptability, as well as the moderating effect of environmental dynamism and organizational absorptive capacity. The results of the research show that (1) the stable environment prefers organizations with a practice strategy of high exploitation and low exploration; (2) environmental dynamism inhibits the impact of both exploitative and exploratory practices on organizational adaptability; and (3) organizational absorptive capacity significantly reinforces the link between the intensity of exploitative practice, as well as exploratory practice, and organizational adaptability. The study investigates the external alignment of organizational exploratory and exploitative practices with environmental dynamism and internal fit with absorptive capacity. The findings provide new insight into the question of how organizations can resist the erosion of environmental dynamism through strategic alignment and capacity development.
\end{abstract}

\section{Introduction}

Organizational adaptability to the environment has long been the theme of extensive attention by researchers in organizational theory and strategic management, as well as business managers [1]. Organizational strategy determines the direction and deployment of organizational development and therefore plays a crucial role in the degree to which the organization matches the external environment, especially the dynamic environment [2]. The formulation of an organization's strategy requires a comprehensive consideration of the organization's internal state and external environment [3]. Cross-sectionally, even if the same strategy is implemented in the same environment, different organizations will achieve varying outcomes due to their own diversity. Longitudinally, if an organization remains committed to its previous strategy in a changing environment, it may not accomplish as much as it did before due to the erosion of environmental dynamism.
The exploration of the complex relationship among environment, strategy, and organizational adaptability had its roots in the internal organization. Whether it is the design school [4], the planning school [5], or the positioning school [6], their focus is all on the relationship between organizational strategy and structure. They have conducted in-depth researches on the question of whether strategy determines structure or structure determines strategy based on population ecology theory [7], contingency theory [8], institutional theory [9], etc. Another school of research focuses on the relationship between the environment in which an organization operates and its strategy. A fundamental question at this point is whether the strategy is completely constrained by the environment or whether the strategy can influence or even dominate the environment [10]. Then, the emergence of the resource-based theory [11] and the capability view [12] brought attention back from the outside of the firm to the inside. Relevant studies have acknowledged the role of organizational resources and capabilities in determining organizational strategy. The concept of dynamic capabilities [13] developed on 
this basis provides the theoretical support for companies to gain through-cycle, sustainable competitive advantage.

Despite the growing amount of literature on organizational adaptability, a limitation that cannot be ignored is that the vast majority of these studies take a single perspective- either inside or outside the organization. We contend that, as an adaptive system with subjective initiative, organizations face multiple complexities from internal conditions, external demands, and objective environments. Organizations make decisions to meet external demands by perceiving the environment, within the constraints of their own resources and capabilities. Organizational adaptability depends on the relative position of the extent of environmental dynamism and the level of organizational competence, rather than on the absolute. Therefore, the investigations based on a single perspective block the interaction between endogenous and exogenous variables concerning environmental adaptability and also make it difficult to examine their joint effects, which are the objective reality of organizational survival and growth.

In response to the limitation of existing studies, this paper conducts a study on organizational adaptability from an integrated, outside-in perspective. While paying attention to the volatility of the environment, it also focuses on one of the organization's core competencies and absorptive capacity. As a key capability for organizations to absorb advanced knowledge from the outside to improve performance and gain competitive advantage, the absorptive capacity itself has received extensive attention in the study of organizational learning and organizational adaptability [14]. However, its coupled role with environmental dynamism has not attracted sufficient attention. Our study provides an opportunity to bridge this gap. Specifically, we establish a computational simulation model. In the model, different degrees of environmental dynamism and varying organizational absorptive capacity are considered. Following the environment-strategy-performance research paradigm, the organizational practice strategy is treated as a key variable. In our results of multiple regression analysis, not only the influences of practice strategy on organizational adaptability are investigated but also the moderating effects of environmental dynamism and absorptive capacity are examined.

The main structure of this paper is organized as follows. First, we introduce the theory related to the research problem and formulate hypotheses based on previous studies. Then, we present a detailed description of the simulation model used and perform model validation and robustness checks. Next, we provide explanations for the results of the computational model and test the hypothesis through the method of multiple regression analysis. Furthermore, we state the implication and limitations of this paper. Some suggestions for future research are also provided. Finally, the conclusions of our study are succinctly presented.

\section{Theoretical Background and Hypotheses Development}

2.1. Organizational Knowledge and Adaptability. Knowledge constitutes an understanding of principles, facts, and processes [15]. Organizational knowledge is the validated understanding and beliefs in an organization about the relationship between the organization and its environment [16]. As a strategic resource, organizational knowledge underpins organizational strategy and action. Although not directly tested by the market, organizational knowledge is recognized as a key antecedent variable of organizational performance [17].

As to organizational adaptability, Chandler thinks, in terms of organizational strategy, that the starting point of business strategy is to adapt to the environment [18]. From a process perspective, Bennis suggests that the organization members need to get involved in coordinating activities, maintain the functioning of organizational systems, and continue to adapt to the external environment [19]. Holding a capability view, Chowdhury suggests that the adaptability of the organization is a capacity for learning and changing [20].

Concerning the relationship between organizational knowledge and adaptability, Peng et al empirically demonstrate that organizational knowledge is the key factor that influences organizational adaptability [21]. The results of Rodan's simulation model show that an increase in the level of individual knowledge of heterogeneity helps the organization to adapt [22]. Peng et al believe that the organization is a complex adaptive system and its adaptability changes with knowledge changing. With the agents increasing their knowledge through knowledge innovation, integration, and configuration, organizational adaptability is improved [23]. A rich knowledge base and an open mind are fundamental requirements for the organization to face the ever-changing business environment [24]. When markets shift, technologies proliferate, competitors multiply, and products become obsolete almost overnight, companies that have a wealth of knowledge or are good at creating knowledge and applying it to the business end are often able to respond appropriately to a dynamic environment. As stated by Nonaka in his discussion of the knowledge-creating company, the one sure source of lasting competitive advantage is knowledge in an economy where the only certainty is uncertainty [25].

Based on the findings of the existing literature, this paper regards the level of organizational knowledge as a measurement of organizational adaptability to the environment. The higher the level of knowledge, the more adaptive the organization is.

2.2. Practice Strategy. The organizational practice strategy is a combination of different intensities, referring to organizational commitments, efforts, and resource allocations, of exploratory and exploitative practices. Exploitative practices are the selection, execution, excavation, and refinement of old certainties. They are intended to better cater to the existing demands of consumers. It is typically characterized by manageable risk, predictable inputs, and the desired payoff period, such as incremental innovation [26]. In contrast, exploratory practices are the search, discovery, experimentation, and risk-taking of new possibilities, which serve potential markets. It is marked by high costs, long 
payoff periods, and uncertain returns, like disruptive innovation [27]. The resource-based view argues that striking the appropriate balance in the allocation of resources between exploitative and exploratory practices is the focus of strategic management of the organization, accommodating both its current survival and future growth. Concentrating on exploratory practices may expose an organization to the pressure of experimental failure and threaten existing activities, while concentrated exploitative practices may cause an organization to reach a suboptimal equilibrium and struggle to acquire a competitive advantage.

From the perspective of knowledge transferring, exploitative practices are the mining, combining, and application of existing knowledge within an organization, while exploratory practices are the import, assimilation, and utilization of fresh knowledge from outside the organization. The implementation of organizational practices requires the support of existing knowledge in the organization. At the same time, they generate new knowledge. The effectiveness of organizational practices is measured by the value of the knowledge they generate, which reflects the organizational performance [28]. The optimal level of organizational knowledge under existing conditions is the relentless pursuit for making and implementing practice strategies. With the elements of the environment remaining unchanged, companies that were underperforming in the past can find best practices, through which their products and services are well-positioned to meet market demands, by making ongoing refinements to their existing practice strategies over time. Companies that otherwise had good performance would fine-tune around the sweet spot to increase the flexibility and fault tolerance of their practice strategies. Given the high risk, long revenue cycles, and uncertainty of return outcomes, managers are naturally very cautious about exploratory practices, especially when more secure alternatives are available. Therefore, we have the following hypothesis:

$\mathrm{H} 1$ : the intensity of exploitative practice has a positive impact on organizational adaptability

$\mathrm{H} 2$ : the intensity of exploratory practice has a negative impact on organizational adaptability

2.3. Environmental Dynamism. Environmental dynamism is defined as the rate of change and the degree of instability of the environment in which organizations operate [29]. The environmental dynamism is reflected in numerous aspects associated with the organization's business, such as new policies in industry regulation, fluctuations in raw material prices, the evolution of manufacturing technology, and changes in consumer preferences. The fluctuation in the environment makes the firm's past routines, and existing profitability modes no longer work as well as before and even threaten the survival of the company. This is essentially a mismatch between the state of the organization's operations and the reality of the moment.

In order to withstand the erosion of the company's performance by environmental dynamism, the company has to make changes. An important part of this change is the adjustment of the company's practice strategy. It was no longer feasible for employees to simply complete their daily tasks. Managers must direct members of the organization to engage in improvement work exploitation or/and exploration. As mentioned above, exploitation is the combination and refinement of an organization's existing knowledge that has proven to be appropriate to the environment in the organization's past practice. However, when the environment changes, this knowledge becomes no longer applicable. Conversely, exploration is experimentation and discovery in areas far from the organization's existing knowledge. Although there is a high risk, it can bring heterogeneous knowledge to the organization. This fresh knowledge can compensate for the loss of organizational knowledge due to environmental changes. Therefore, we have the following hypothesis:

H3a: the environmental dynamism moderates (weakens) the positive impact of the intensity of exploitative practice on organizational adaptability

H3b: the environmental dynamism moderates (weakens) the negative impact of the intensity of exploratory practice on organizational adaptability

2.4. Absorptive Capacity. Absorptive capacity is defined as the ability to recognize, assimilate, and apply new knowledge [30]. What we are discussing here is the organization's absorptive capacity, which depends on the absorptive capacity of its individual members, but is not simply the sum of the individuals. Organizations possessing high absorptive capacity typically demonstrate superior performance in knowledge search, information value capture, integration of old and new knowledge, and commercialization of knowledge. The idea that organizational absorptive capacity is an important potential source of competitive advantage, innovation, and organizational performance has been extensively validated and accepted [31, 32].

Organizational absorptive capacity reflects the speed of the organization in processing knowledge. As an organization's absorptive capacity increases, it will evolve to become more agile in knowledge treatment, which means that it can handle more knowledge in the same amount of time than before. Under such circumstances, organizations need to increase their efforts to bring in knowledge from outside in order to fully realize the potential of the organization's absorptive capacity to avoid resulting in capacity redundancy. After a large amount of external heterogeneous knowledge flows into the organization, which usually is kept in the minds of individuals, members in the organization need to apply the knowledge to the business related to themselves through communication, screening, and combination. If this process of horizontal socialization is absent, the organization's efforts to introduce new knowledge will not achieve the expected results and will only bear the cost pressure of experimentation for nothing. Therefore, we have the following hypothesis: 
H4a: the absorptive capacity moderates (reinforces) the positive impact of the intensity of exploitative practice on organizational adaptability

H4b: the absorptive capacity moderates (reinforces) the negative impact of the intensity of exploratory practice on organizational adaptability

Integrating the above theoretical analysis, we present a conceptual research framework in Figure 1.

\section{Methodology}

In this article, agent-based simulation modeling is adopted as the research method. Compared to empirical methods such as questionnaires, computational modeling enables the implementation of experiments that cannot be performed in the real world, functioning as a favorable complement to empirical investigations [33]. Additionally, the simulation modeling approach requires more stringent accuracy and logical consistency than verbal theoretical development, and it calls for fewer assumptions and constraints than analytical models [34]. These advantages make computational simulation modeling as an effective tool for use in a wide range of fields such as organization theory and strategic management [35].

We choose March's model [36] as a specific research tool. First, March's model is proposed in the context of organizational learning. As an outcome of organizational learning, the organizational and individual knowledge of any learning cycle can be obtained from the model. In our paper, organizational knowledge is treated as a measure of organizational adaptability. The calculations of the model are consistent with the outcome variables adopted in this paper. Second, in the mutual learning of organization and individual described by March's model, individual learning from the organization is defined as exploitation, while individual bringing in knowledge from outside is considered as exploration. As mentioned above, this paper views practice strategies as a combination of exploratory and exploitative practices. The definition of the model matches the research design of this paper. Third, the internal moderating variable in this paper, absorptive capacity, can be mapped to learning by the organization from individuals in the model, while the external moderating variable, environmental dynamism, is clearly defined in the model. In summary, March's model fits well with this paper both in terms of research purpose and design. Furthermore, considering the great influence of this classical model, the numerous simulation studies $[3,22$, 37,38 ] derived from it can provide us with a wide range of reference and calibrated coordinate systems. For the sake of improving simulation efficiency, different from using Basic programming language in March's research, we choose the MATLAB software platform because of its natural superiority for matrix calculations.

3.1. Model Description. In the model, the environment in which the organization survives is set as an $m$-dimensional vector, and the value of each dimension is initialized with equal probability $(1 / 2)$ to 1 or -1 , indicating the specific state

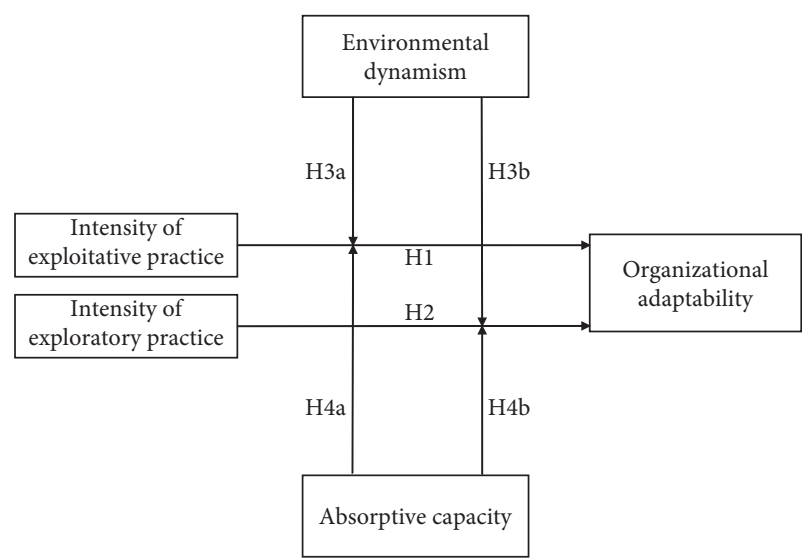

FIgURE 1: Research framework.

of the environment in different aspects. The organization is expressed as a matrix with $n$ rows and $m$ columns, representing that there are $n$ members in the organization, and each member has the same knowledge dimension $(m)$ as the environment in which he or she lives. The value at each position in the matrix is randomly picked with probability $1 /$ 3 from the set [ $\left[\begin{array}{lll}-1 & 0 & 1\end{array}\right]$ before the calculation starts. If an individual has the same value $(-1$ or 1$)$ as the environment on a dimension, the individual is considered to have the correct knowledge of this dimension and vice versa. A value of " 0 " indicates a lack of awareness of the environment. Organizational knowledge is defined in the initial stage as an $m$-dimensional zero vector.

In each learning cycle, previous-period organizational and individual knowledge levels are calculated first by dividing the number of dimensions they, respectively, match with the environment by $m$. Then, all individuals with a higher level of knowledge than the organization are selected to form the learning objectives of the organization. For each dimension, the dominant cognition of the learning object is determined according to the number of different nonzero values. Subsequently, if the organization's value on this dimension is different from the dominant value of the learning objectives, the organization learns with probability $p_{2}$ from each individual who has the dominant value. This is the process of learning from individuals by the organization. After that, the individual will also learn from the previousperiod organization. For each nonzero dimension in the organizational knowledge, if the dimension in the individual corresponding to it has a different value, the value of that dimension in the individual will be updated to that in the organizational knowledge with probability $p_{1}$. The above is the complete procedure of mutual learning between organization and individual. When mutual learning is over, each vector in the organization is replaced with a new vector, which is generated in a similar random way, with probability $p_{3}$. Finally, the value of each dimension in the environment changes to its opposite value (from 1 to -1 or from -1 to 1 ), with probability $p_{4}$.

In the model, the knowledge level is expressed as the ratio of the number of dimensions of correct knowledge to that of total knowledge dimensions $(m)$. The correctness of 


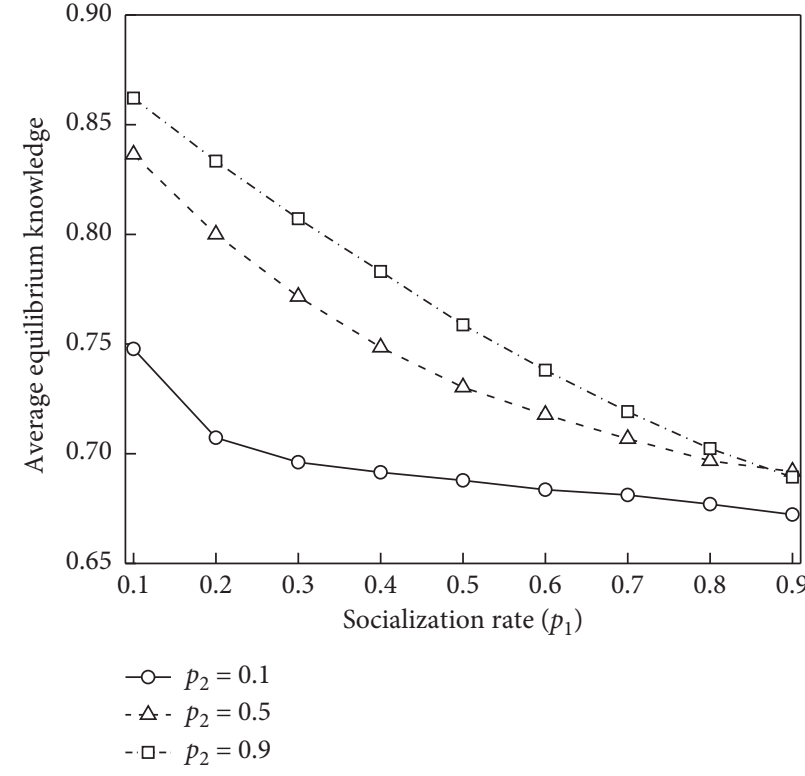

(a)

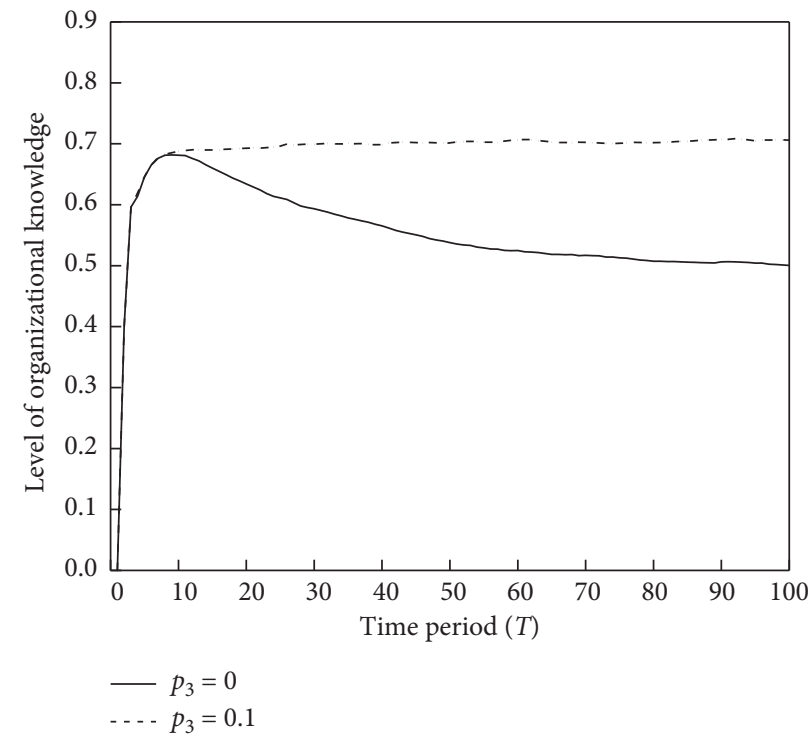

(b)

FIgURE 2: Result of replication. (a) Effect of learning rates $\left(p_{1}, p_{2}\right)$ on level of organizational knowledge in a stable environment $\left(p_{3}=0\right.$; $\left.p_{4}=0\right)$. (b) Effect of environmental dynamism $\left(p_{4}=0.02\right)$ on level of organizational knowledge, with and without the inflow of external knowledge $\left(p_{1}=0.5 ; p_{2}=0.5\right)$.

knowledge on a certain dimension is determined by whether the value of the organizational (individual) knowledge on the targeted dimension is consistent with that of the environmental state. The parameter $p_{1}$ reflects the rate of organizational members learning from the organization, which maps to the organizational exploitative practices. The larger the value of $p_{1}$, the greater the intensity of exploratory practices. The parameter $p_{2}$ signifies the speed at which the organization learns from individual members, which is considered to be a function of the organizational absorptive capacity. A larger value of $p_{2}$ indicates that the organization possesses a superior absorptive capacity. The speed of fresh knowledge inflow or the intensity of exploratory practices is controlled by parameter $p_{3}$. The weaker intensity of organizational exploratory practices corresponds to a smaller value of $p_{3}$. Finally, it is noticeable that the environment becomes increasingly turbulent as the value of the parameter $p_{4}$ increases. All four parameters have values ranging from 0 to 1 .

3.2. Model Reconstruction and Verification. Following the textual description above, we reconstructed the model and replicated Figure 1 (pp. 76) and Figure 5 (pp. 80) from March's article, which are closely related to our study. The result of the replication is shown in Figure 2. Since we do not seek the source code of March, we use the method of comparing the results of the replicated model with that of the original model to verify if our model is correct. After comparison, we find that there are significant differences between our results and March's article, both in terms of qualitative and quantitative relationships. Although this does not affect the validity of the main conclusions in March's article, it would be a destructive blow to the robustness of our findings, as the correct establishment of the model is the cornerstone for further extensions. After a targeted search, we find that Chanda and Miller [39] encountered the same problem in their study. The difference is that they managed to get the source code from Professor James March. They then critically compared March's textual elaboration of the model with the original program code. As a result, they found that there are three major disparities between the text and the code-net correct belief, random classification of zero beliefs, and twostep updating (see reference [39]), which are not mentioned in the official script. Furthermore, they confirmed that even after removing these additional settings from the code, the key findings in March's article still hold. After critiquing the theoretical and logical irrationality of these additional settings, as a conclusion, they propose that the results presented in Figure 1 (pp. 10) of their paper should be considered as the baseline for future replication and extension work based on March's model.

As suggested by Chanda and Miller, we compare Figures 2(a) and 2(b) in this paper with Figures 1(a) and 1(e), respectively. The results of the comparison show that both are not only identical in their qualitative relationships but also have the same values at the corresponding positions, ignoring the negligible errors due to complete randomness. This fact directly confirms the validity of our code and the accuracy of our model and provides a solid foundation for further research in the following.

3.3. Robustness Check. Following March (1991), the number of organizational members is $50(n=50)$, and the dimension of knowledge is set to $30(m=30)$ in all experiments shown 


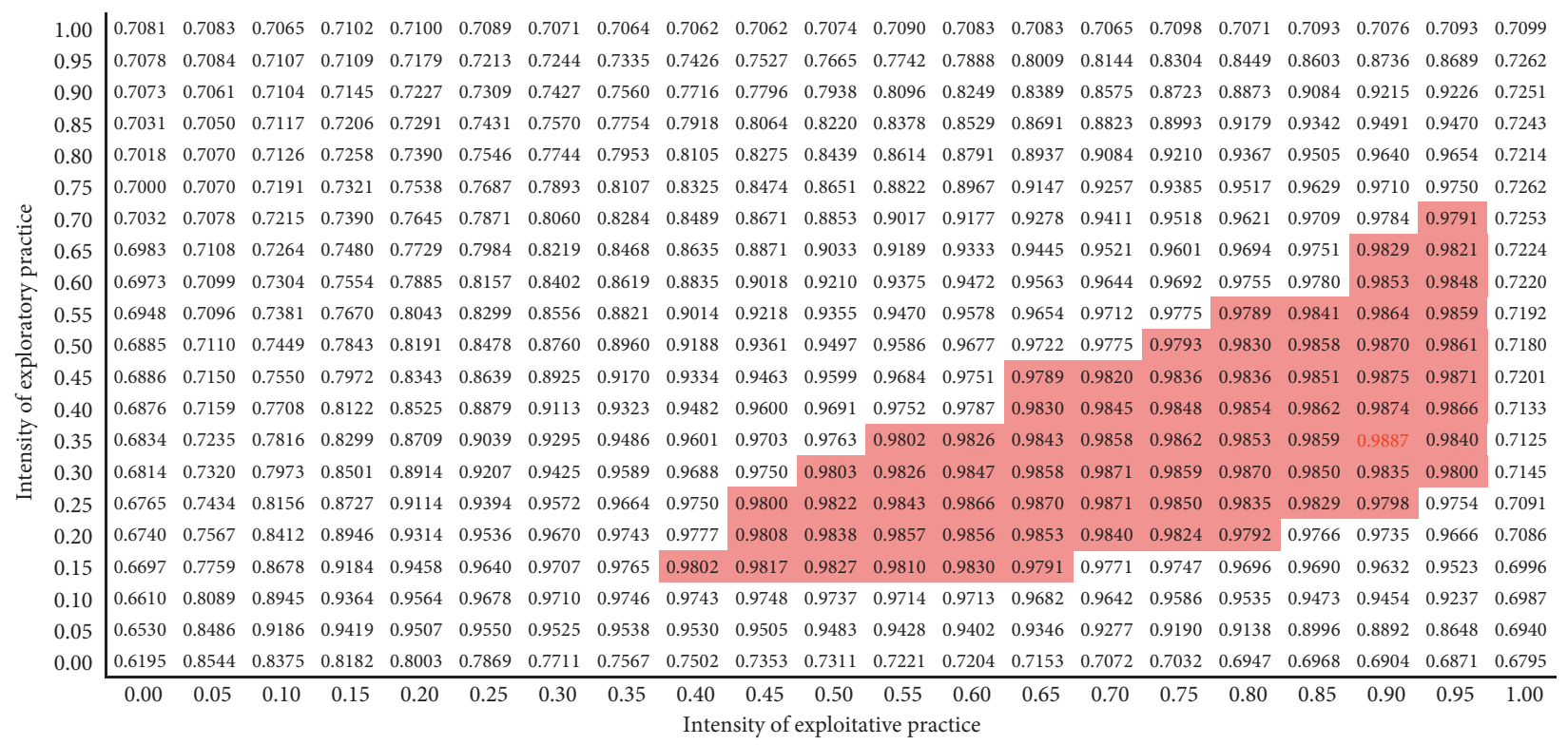

FIgURE 3: Effect of practice strategy on organizational adaptability.

in this paper. The results of the code program are recorded and analyzed after 100 cycles of operation $(T=100)$. Different from March (1991), each model in our experiments undergoes 1000 iterations $(I=100)$ instead of 80 , and their average is employed, in order to reduce the data fluctuations generated by the random process. The most significant influence of this change on the results is the smoother data curves. To ensure the robustness of the conclusions, we perform robustness checks on all tests. Similar to Chanda and Ray [38], we vary, in steps of 5 units, the number of organizational members $(n)$ from 40 to 60 , the dimension of knowledge $(\mathrm{m})$ from 20 to 40, and the number of periods of simulation $(T)$ from 90 to 110 . Consequently, we acquire similar qualitative results for different parameter settings. This demonstrates the rigidity of the outcomes of this paper.

\section{Results}

As mentioned in Section 2.1, we regard the level of organizational knowledge as a measure of the organization's adaptability to its environment. Considering that the level of organizational knowledge can be directly calculated in March's model, in this way, organizational adaptability will be able to be visually examined by the computational outcomes. A larger value of the result means stronger organizational adaptability. Moreover, the evaluation of organizational adaptability in the real world is essentially based on relative rather than absolute principles. Managers can adjudge that organizational adaptability has gained strength according to the improvement in company performance at a certain stage, but they do not have the means to identify the maximum value of organizational adaptability, due to the bounded rationality [40]. Therefore, here, we use an approach similar to Chanda and Ray's [38], which regards the value within a $1 \%$ (not included) range of the largest one as optimum. The optimal value of organizational adaptability reflects the level of managers' expectations and satisfaction with organizational performance. All optimal values are considered to be equivalent. In the results shown below, the maximum values are marked in red and bolded, and the optimal values are shaded.

4.1. Effects of Practice Strategy. We first investigate the effect of different combinations of the intensity of exploratory and exploitative practices on the organizational adaptability in a stable environment $\left(p_{4}=0\right)$, with a moderate organizational absorptive capacity $\left(p_{2}=0.5\right)$. The results are shown in Figure 3 .

In Figure 3, the optimal values occur in the range of intensity of exploratory practices from 0.15 to 0.70 . Exploratory practices with intensities below 0.15 cannot achieve satisfactory outcomes because too low levels of exploration cannot import sufficient heterogeneous knowledge from the outside world. This leads to the idleness of the organization's absorptive capacity. On the other hand, exploratory practices with an intensity greater than 0.70 also do not obtain the desired expectations because high levels of exploration bring in a volume of knowledge that exceeds the limits of absorptive capacity, creating knowledge redundancy. In addition, the influx of a large amount of external knowledge also causes a shock to the original knowledge structure of the organization, resulting in a reduction of the organizational knowledge level. The optimal range of intensity of exploitative practices is from 0.40 to 0.95 . When the intensity is less than 0.40 , organizational members cannot take full advantage of the potential of existing knowledge. On the contrary, too high intensity of exploitative practices (greater than 0.95 ) results in a rapid reduction in the heterogeneity between organizational and members' knowledge, which in turn diminishes the opportunity for organizational learning and advancement, shown in the figure as an abrupt decline in the organizational adaptability. 
The horizontal coordinate value of any point in the shading is greater than the vertical coordinate value. This suggests that the combination of higher intensity of exploitative practices with lower intensity of exploratory practices in a stable environment is a fundamental principle of effective organizational practice strategies. When the environment remains unchanged, the existing knowledge stocks of the organization are sufficient for it to produce good adaptability. At this time, too much introduction of external knowledge will instead destroy the nice appropriateness between the two. Moreover, the organization in this state usually does not have a strong willingness to import external knowledge and naturally will not allocate too many resources in this regard. On the contrary, the organization only needs to implement incremental innovation on the current basis according to its own business objectives and development needs to maintain exceptional organizational performance.

4.2. Effects of Environmental Dynamism. Figure 4 shows the results of the impact of different levels of environmental dynamism on organizational adaptability and practice strategy, with a moderate organizational absorptive capacity $\left(p_{2}=0.5\right)$. Referring to similar settings in the relevant literature [3,36], the values of $p_{4}$ are set to 0.005 (Figure 4(a)), 0.01 (Figure 4(b)), 0.02 (Figure 4(c)), respectively, representing slight, moderate, and extreme dynamism of the environment. A higher value is not adopted since a 0.02 value for $p_{4}$ means that the entire reality changes $100 \%$ twice in 100 time steps, which could be 100 weeks or months, or quarters in the real world. If the reality changes any faster, there is no difference when an organization takes actions based on learning (there is nothing to learn-most knowledge becomes obsolete very quickly) vis-a-vis when the organization takes random actions.

The maximum values of the results in Figures 4(a)-4(c) are $0.8818,0.8081$, and 0.7253 , respectively. This indicates that the adaptability of the organization to the environment decreases with the degree of environmental dynamism. A change in the environment in a certain dimension makes the organization's past best practices in that area no longer work. As the environment changes in more and more aspects, the organization's advancement in these areas will be destroyed. In pursuit of optimal adaptability, the range of intensity of exploratory and exploitative practices migrates as the environment changes. In the slight, medium, and severe environmental dynamism, the ranges of the intensity of exploratory practice are $0.20-0.60,0.15-0.55$, and $0.20-0.55$, respectively. As the environmental dynamism grows, the starting point of the range of intensity of exploratory practices corresponding to the optimal value decreases and then increases, and the endpoint decreases and then stabilizes. In Figure 4, the ranges of the intensity of exploitative practice are $0.50-0.90,0.45-0.85$, and $0.30-0.80$ in that order. Both the values of the starting point and the endpoint decrease with the increase in environmental dynamism, which is expressed visually in the figure as an overall leftward shift of the shading. This indicates that environmental dynamism has a significant negative effect on the exploitative practices of the organization, and the strength of this negative effect is positively related to the degree of turbulence.

4.3. Effects of Absorptive Capacity. Figure 5 illustrates the results of the impact of different absorptive capacities on organizational adaptability and practice strategy, in the moderately dynamic environment $\left(p_{4}=0.01\right)$. Figure $5(\mathrm{~b})$ is the same as Figure 4(b). For a better comparative analysis, it is shown repeatedly here.

The maximum values of the results in Figures 5(a)-5(c) are $0.6603,0.8081$, and 0.8628 , respectively. This indicates that the adaptability of the organization to the environment increases with the absorptive capacity. The improved absorptive capacity allows organizations to more accurately identify, more quickly absorb, and more effectively utilize new knowledge, whether it already exists internally or has been imported from outside. As can be seen in Figure 5, when the organization's absorptive capacity changes from low to medium, the range of intensity of exploratory practice keeps unchanged, 0.15-0.55. However, when the absorptive capacity changes from medium to high, both the starting and endpoint of the range of intensity of exploratory practices corresponding to the optimal value increase from 0.15 to 0.20 for the starting point and from 0.55 to 0.65 for the endpoint. This result suggests that while an organization's absorptive capacity is positively correlated with the intensity of its exploratory practices, this is only relative to organizations that have good absorptive capacity themselves. If the organization itself has poor absorptive capacity, then normal capacity enhancement may not motivate the organization to strengthen exploratory practices, under the pressure of pursuing optimal performance. For the organization of low, medium, and high absorptive capacity, the ranges of the intensity of exploitative practice are $0.10-0.65,0.45-0.85$, and $0.55-0.90$, respectively. As absorptive capacity grows, the intensity of exploitative practices increases more significantly compared to the exploratory practice.

4.4. Result of Regression Method. Although the above results provide a qualitative analysis of the direction of influence of the independent and moderating variables on the dependent variable to a certain degree, the extent of their influence on the dependent variable and the robustness of the findings are not reliably described. To solve this problem, multiple regression analysis (MRA) is carried out to test the hypotheses further. The result of the regression is shown in Table 1 . Model 1 includes only independent and moderating variables. Model 2 adds all the interaction terms. We can see that VIF associated with each regression coefficient equals 1.000. Therefore, the model does not suffer from multicollinearity. The $R$-square value of the dependent variable is 0.481 , suggesting that relatively substantial variances in the construct are explained by the research model. The addition of the interaction terms in Model 2 increases the $R$-square value significantly compared with Model $1\left(\Delta R^{2}=.033\right.$, $p<0.001$ ), in support of the significant moderating effects of $\mathrm{ED}$ and $\mathrm{AC}$. 


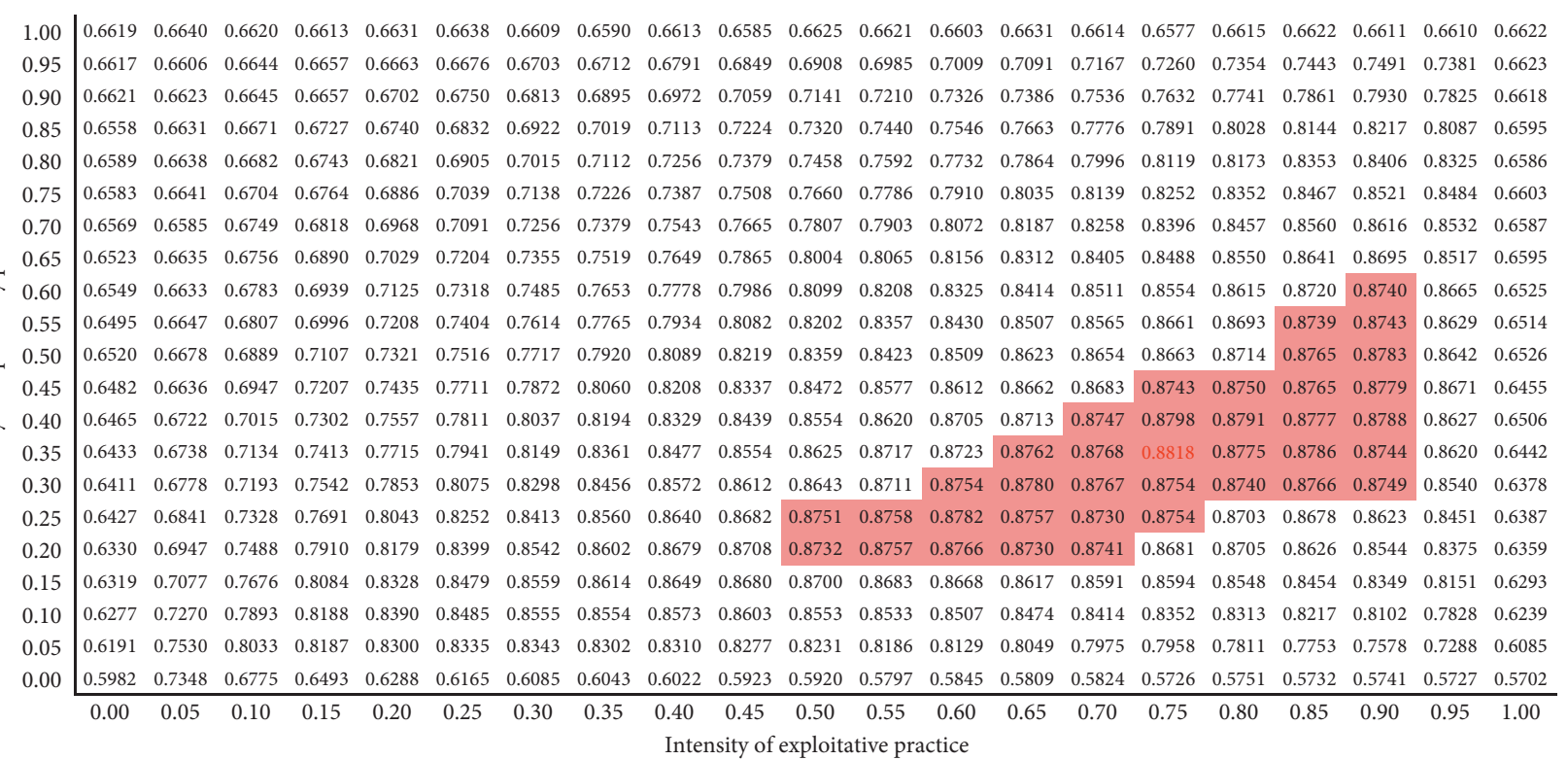

(a)

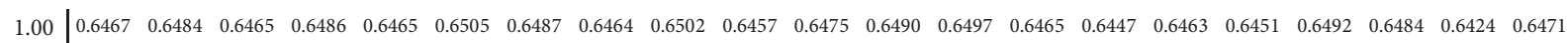
$\begin{array}{lllllllllllllllllllllllllll}0.95 & 0.6463 & 0.6452 & 0.6492 & 0.6488 & 0.6507 & 0.6494 & 0.6548 & 0.6575 & 0.6604 & 0.6660 & 0.6691 & 0.6657 & 0.6719 & 0.6774 & 0.6852 & 0.6871 & 0.6931 & 0.6932 & 0.6913 & 0.6861 & 0.6504\end{array}$ $\begin{array}{lllllllllllllllllllllllll}0.90 & 0.6445 & 0.6452 & 0.6478 & 0.6533 & 0.6541 & 0.6606 & 0.6596 & 0.6646 & 0.6717 & 0.6726 & 0.6818 & 0.6912 & 0.6967 & 0.7048 & 0.7084 & 0.7143 & 0.7231 & 0.7292 & 0.7245 & 0.7167 & 0.6501\end{array}$ $\begin{array}{llllllllllllllllllllllllll}0.85 & 0.6459 & 0.6502 & 0.6534 & 0.6548 & 0.6593 & 0.6636 & 0.6725 & 0.6770 & 0.6836 & 0.6897 & 0.6956 & 0.7011 & 0.7152 & 0.7216 & 0.7294 & 0.7401 & 0.7464 & 0.7475 & 0.7476 & 0.7304 & 0.6444\end{array}$ $\begin{array}{lllllllllllllllllllllllll}0.80 & 0.6422 & 0.6503 & 0.6502 & 0.6577 & 0.6651 & 0.6713 & 0.6761 & 0.6879 & 0.6934 & 0.7073 & 0.7078 & 0.7219 & 0.7302 & 0.7435 & 0.7501 & 0.7567 & 0.7628 & 0.7659 & 0.7638 & 0.7529 & 0.6452\end{array}$ $\begin{array}{llllllllllllllllllllll}0.75 & 0.6446 & 0.6495 & 0.6518 & 0.6600 & 0.6685 & 0.6763 & 0.6843 & 0.6947 & 0.7046 & 0.7114 & 0.7272 & 0.7339 & 0.7421 & 0.7540 & 0.7579 & 0.7678 & 0.7726 & 0.7775 & 0.7741 & 0.7547 & 0.6428\end{array}$ $\begin{array}{lllllllllllllllllllllllllll}\mathscr{\Xi} & 0.70 & 0.6433 & 0.6481 & 0.6581 & 0.6664 & 0.6726 & 0.6846 & 0.6954 & 0.7018 & 0.7137 & 0.7226 & 0.7355 & 0.7465 & 0.7544 & 0.7651 & 0.7729 & 0.7726 & 0.7821 & 0.7832 & 0.7822 & 0.7620 & 0.6422\end{array}$ $\begin{array}{llllllllllllllllllllllll} & 0.65 & 0.6407 & 0.6449 & 0.6602 & 0.6668 & 0.6767 & 0.6906 & 0.7036 & 0.7146 & 0.7256 & 0.7348 & 0.7479 & 0.7554 & 0.7662 & 0.7733 & 0.7798 & 0.7858 & 0.7883 & 0.7883 & 0.7902 & 0.7704 & 0.6385\end{array}$

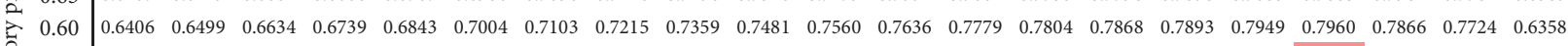
\begin{tabular}{ll|lllllllllllllllllllllllll} 
苟 & 0.55 & 0.6426 & 0.6509 & 0.6626 & 0.6760 & 0.6933 & 0.7065 & 0.7221 & 0.7354 & 0.7432 & 0.7602 & 0.7705 & 0.7767 & 0.7808 & 0.7868 & 0.7939 & 0.7953 & 0.7981 & 0.8015 & 0.7919 & 0.7694 & 0.6358
\end{tabular} \begin{tabular}{lllllllllllllllllllllllllll} 
& 0.55 & 0.6426 & 0.650 & 0.6626 & 0.6760 & 0.6933 & 0.7065 & 0.7221 & 0.7354 & 0.7432 & 0.7602 & 0.7705 & 0.7767 & 0.7808 & 0.7868 & 0.7939 & 0.7953 & 0.7981 & 0.8015 & 0.7919 & 0.7694 & 0.6358 \\
\hline & 0.50 & 0.6403 & 0.6508 & 0.6674 & 0.6826 & 0.6982 & 0.7149 & 0.7318 & 0.7449 & 0.7595 & 0.7693 & 0.7766 & 0.7838 & 0.7880 & 0.7973 & 0.7982 & 0.8006 & 0.8043 & 0.8000 & 0.7934 & 0.7745 & 0.6356
\end{tabular}

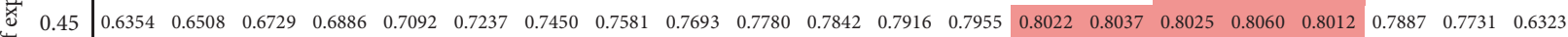
$\begin{array}{llllllllllllllllllllllllll}\breve{\circ} & 0.45 & 0.6354 & 0.6508 & 0.6729 & 0.6886 & 0.7092 & 0.7237 & 0.7450 & 0.7581 & 0.7693 & 0.7780 & 0.7842 & 0.7916 & 0.7955 & 0.8022 & 0.8037 & 0.8025 & 0.8060 & 0.8012 & 0.7887 & 0.7731 & 0.6323 \\ & 0.6346 & 0.6523 & 0.6741 & 0.6946 & 0.7184 & 0.7420 & 0.7524 & 0.7633 & 0.7742 & 0.7876 & 0.7933 & 0.7923 & 0.7992 & 0.8032 & 0.8047 & 0.8035 & 0.8037 & 0.8001 & 0.7950 & 0.7732 & 0.6286\end{array}$ $\begin{array}{llllllllllllllllllllllllll}\text { s. } & 0.35 & 0.6363 & 0.6552 & 0.6827 & 0.7078 & 0.7290 & 0.7447 & 0.7640 & 0.7729 & 0.7849 & 0.7903 & 0.7973 & 0.8035 & 0.8057 & 0.8054 & 0.8027 & 0.8048 & 0.8008 & 0.7933 & 0.7934 & 0.7712 & 0.6276\end{array}$ $\begin{array}{lllllllllllllllllllllllll}\text { 岌 } 0.30 & 0.6300 & 0.6586 & 0.6874 & 0.7149 & 0.7375 & 0.7574 & 0.7720 & 0.7844 & 0.7887 & 0.7994 & 0.8009 & 0.8039 & 0.8045 & 0.8074 & 0.8029 & 0.8061 & 0.7988 & 0.7976 & 0.7909 & 0.7613 & 0.6224\end{array}$ $\begin{array}{llllllllllllllllllllllllll}0.25 & 0.6297 & 0.6610 & 0.6992 & 0.7286 & 0.7529 & 0.7711 & 0.7827 & 0.7910 & 0.7937 & 0.7983 & 0.8056 & 0.8030 & 0.8042 & 0.8081 & 0.8037 & 0.7965 & 0.7965 & 0.7943 & 0.7834 & 0.7561 & 0.6174\end{array}$ \begin{tabular}{l|lllllllllllllllllllllllll}
0.20 & 0.6271 & 0.6742 & 0.7098 & 0.7430 & 0.7594 & 0.7794 & 0.7859 & 0.7957 & 0.7975 & 0.8003 & 0.8068 & 0.8023 & 0.8059 & 0.8009 & 0.7949 & 0.7940 & 0.7919 & 0.7837 & 0.7742 & 0.7486 & 0.6103
\end{tabular} $\begin{array}{llllllllllllllllllllllllll}0.15 & 0.6207 & 0.6773 & 0.7279 & 0.7481 & 0.7725 & 0.7830 & 0.7867 & 0.7954 & 0.7947 & 0.8011 & 0.7991 & 0.7947 & 0.7967 & 0.7928 & 0.7856 & 0.7829 & 0.7761 & 0.7729 & 0.7575 & 0.7342 & 0.6077\end{array}$ $\begin{array}{lllllllllllllllllllllll}0.10 & 0.6203 & 0.6920 & 0.7363 & 0.7591 & 0.7736 & 0.7849 & 0.7849 & 0.7868 & 0.7864 & 0.7876 & 0.7817 & 0.7779 & 0.7790 & 0.7767 & 0.7714 & 0.7667 & 0.7577 & 0.7518 & 0.7330 & 0.7076 & 0.6036\end{array}$ $\begin{array}{llllllllllllllllllllllllll}0.05 & 0.6140 & 0.7145 & 0.7475 & 0.7542 & 0.7625 & 0.7670 & 0.7651 & 0.7654 & 0.7600 & 0.7593 & 0.7506 & 0.7499 & 0.7400 & 0.7384 & 0.7355 & 0.7289 & 0.7153 & 0.7108 & 0.6929 & 0.6614 & 0.5847\end{array}$ $\begin{array}{lllllllllllllllllllllll}0.00 & 0.5983 & 0.6692 & 0.5973 & 0.5761 & 0.5595 & 0.5464 & 0.5432 & 0.5415 & 0.5409 & 0.5354 & 0.5413 & 0.5304 & 0.5368 & 0.5288 & 0.5333 & 0.5315 & 0.5262 & 0.5256 & 0.5291 & 0.5290 & 0.5296\end{array}$ $\begin{array}{lllllllllllllllllllll}0.00 & 0.05 & 0.10 & 0.15 & 0.20 & 0.25 & 0.30 & 0.35 & 0.40 & 0.45 & 0.50 & 0.55 & 0.60 & 0.65 & 0.70 & 0.75 & 0.80 & 0.85 & 0.90 & 0.95 & 1.00\end{array}$ Intensity of exploitative practice

(b)

Figure 4: Continued. 


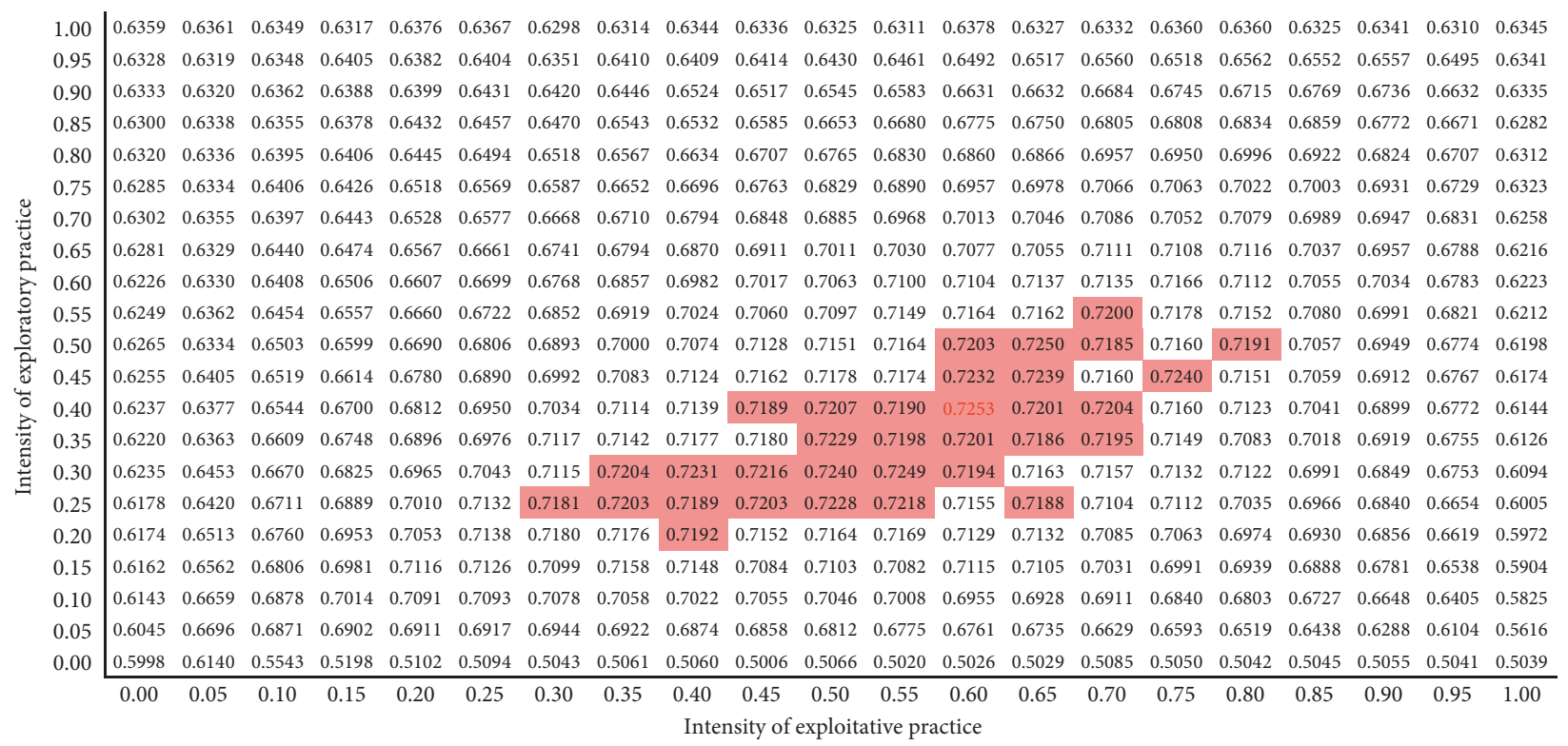

(c)

FIGURE 4: Effect of environmental dynamism on organizational adaptability and practice strategy. (a) $p_{4}=0.005$. (b) $p_{4}=0.01$. (c) $p_{4}=0.02$.

To further facilitate these interpretations, we plot, in Figure 6, the effects of IIP and IRP on OA for low and high levels of two moderators (ED and AC), respectively. Based on the range of parameter values in the model, we define 0.005 as the low level of ED and 0.02 as the high level; 0.1 as the low level of AC; and 0.9 as the high level. Following Dawson's suggestion [41], we conduct simple slope tests to know more about the specific relationship between the predictors (IIP and IRP) and outcome variables (OA) at particular levels of moderators (ED and AC). The result of the test is shown in Table 2.

The result in Figure 6 and Table 2 provides a more detailed interpretation of the effect of the moderators. It shows that where ED is low, there is a positive relationship between IIP and OA, but a high level of ED gives a significant negative relationship between them. When ED is low, there is little relationship between IRP and OA. However, when at a high level of ED, there is a strong positive relationship between IRP and OA. The results demonstrate that the relationship between IIP and OA is always positive whether at a low or high level of AC, but it is far more so where AC is high. Similarly, the relationship between IRP and OA is always negative significantly whether at a low or high level of AC, but it is far more so where $\mathrm{AC}$ is high.

In order to analyze more intuitively the effect of the independent and moderating variables, we demonstrate in Figure 7 the main indicators of MRA for the research model. As presented in Figure 7, the influence of IIP on OA is significantly positive $(\beta=.211, p<0.001)$; thus, hypothesis 1 is supported. It is also shown that the link between IRP and $\mathrm{OA}$ is significantly negative $(\beta=-0.127, p<0.001)$, providing evidence for hypothesis 2 . With regard to the moderating effect, ED has a significant weakening impact on the relationship between IIP and OA $(\beta=-0.114, p<0.001)$, as well as that between IRP and OA $(\beta=-0.107, p<0.001)$. Hypothesis $3 \mathrm{a}$ and $3 \mathrm{~b}$ are supported. It is worth attention that ED has a significant negative effect on OA $(\beta=-0.519$, $p<0.001$ ); hence, it has a significant alternative relationship with IRP in affecting OA. On the contrary, AC significantly strengthens the link between IIP and OA $(\beta=.079$, $p<0.001)$, and that between IRP and OA $(\beta=-0.044$, $p<0.001)$. Therefore, hypotheses $4 \mathrm{a}$ and $4 \mathrm{~b}$ are supported.

4.5. Effects of Practice Time. The above analysis is carried out on the basis of data of 100 time periods. Although such cross-sectional data provide a nice demonstration of the effect of the independent and moderating variables on the dependent variable, it lacks consideration of the time factor, which is a very important dimension of organizational adaptability to be examined. After all, whether it is theoretical research or management practice, they are more concerned with the long-term performance of an organization under a certain combination of diverse constraints than with the instantaneous or short-term success. Therefore, this paper conducts an additional study based on longitudinal data with a perspective of development. Specifically, we investigate the time effects of the two moderating variables of this paper, environmental dynamism and absorptive capacity, on the organizational adaptability. The results are presented in Figure 8. From Figure 8(a), we can see that the organizational knowledge first increases and then remains essentially constant over time for varying levels of environmental dynamism. At the same point in time, the higher the environmental dynamism, the lower the organizational knowledge. Moreover, the knowledge gap between different levels of dynamism is substantially immutable over time. Figure 8(b) demonstrates the monotonically incremental relationship of organizational 


\begin{abstract}
\begin{tabular}{l|lllllllllllllllllllll}
1.00 & 0.5951 & 0.5946 & 0.5963 & 0.5941 & 0.5928 & 0.5968 & 0.5955 & 0.5934 & 0.5942 & 0.5953 & 0.5964 & 0.5964 & 0.5954 & 0.5949 & 0.5993 & 0.5968 & 0.5951 & 0.5966 & 0.5962 & 0.5953 & 0.5955
\end{tabular}
$\begin{array}{lllllllllllllllllllllllllll}0.95 & 0.5969 & 0.5959 & 0.5964 & 0.5985 & 0.6002 & 0.6004 & 0.6007 & 0.6053 & 0.6044 & 0.6086 & 0.6096 & 0.6154 & 0.6189 & 0.6167 & 0.6176 & 0.6221 & 0.6216 & 0.6194 & 0.6207 & 0.6107 & 0.6098\end{array}$ $\begin{array}{llllllllllllllllllllll}0.90 & 0.5901 & 0.5957 & 0.5966 & 0.5989 & 0.6041 & 0.6049 & 0.6112 & 0.6110 & 0.6117 & 0.6195 & 0.6227 & 0.6225 & 0.6255 & 0.6291 & 0.6297 & 0.6352 & 0.6283 & 0.6296 & 0.6257 & 0.6193 & 0.6036\end{array}$

$\begin{array}{lllllllllllllllllllllllll}0.85 & 0.5964 & 0.5961 & 0.5972 & 0.6030 & 0.6053 & 0.6118 & 0.6161 & 0.6210 & 0.6246 & 0.6278 & 0.6296 & 0.6297 & 0.6324 & 0.6347 & 0.6363 & 0.6351 & 0.6401 & 0.6352 & 0.6295 & 0.6200 & 0.6044\end{array}$ $\begin{array}{llllllllllllllllllllllll}0.80 & 0.5957 & 0.5971 & 0.6008 & 0.6067 & 0.6129 & 0.6148 & 0.6224 & 0.6287 & 0.6302 & 0.6318 & 0.6405 & 0.6392 & 0.6401 & 0.6437 & 0.6409 & 0.6445 & 0.6358 & 0.6340 & 0.6325 & 0.6208 & 0.6043 & 0.63\end{array}$ $\begin{array}{lllllllllllllllllllllllllll}0.75 & 0.5985 & 0.6012 & 0.6026 & 0.6125 & 0.6138 & 0.6214 & 0.6273 & 0.6315 & 0.6355 & 0.6412 & 0.6425 & 0.6436 & 0.6458 & 0.6494 & 0.6413 & 0.6398 & 0.6437 & 0.6333 & 0.6274 & 0.6220 & 0.6027\end{array}$

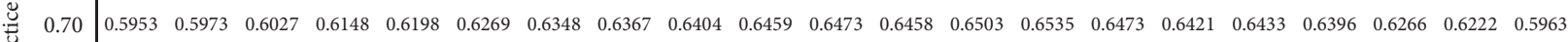
$\begin{array}{lllllllllllllllllllllll}\widetilde{\breve{g}} & 0.65 & 0.5946 & 0.6018 & 0.6077 & 0.6191 & 0.6232 & 0.6287 & 0.6351 & 0.6451 & 0.6473 & 0.6507 & 0.6524 & 0.6518 & 0.6515 & 0.6499 & 0.6441 & 0.6460 & 0.6372 & 0.6384 & 0.6266 & 0.6205 & 0.6015\end{array}$ $\begin{array}{lllllllllllllllllllllll}3 & 0.60 & 0.5923 & 0.6003 & 0.6129 & 0.6223 & 0.6281 & 0.6391 & 0.6437 & 0.6463 & 0.6498 & 0.6528 & 0.6499 & 0.6536 & 0.6520 & 0.6476 & 0.6492 & 0.6414 & 0.6359 & 0.6356 & 0.6260 & 0.6167 & 0.5963\end{array}$

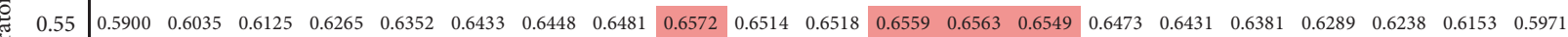
$\begin{array}{lllllllllllllllllllllllll}\stackrel{\overrightarrow{0}}{0} & 0.50 & 0.5879 & 0.6040 & 0.6197 & 0.6277 & 0.6417 & 0.6487 & 0.6523 & 0.6532 & 0.6565 & 0.6573 & 0.6524 & 0.6539 & 0.6496 & 0.6505 & 0.6413 & 0.6392 & 0.6355 & 0.6281 & 0.6201 & 0.6108 & 0.5959\end{array}$ \begin{tabular}{ll|llllllllllllllllllllll} 
ex & 0.45 & 0.5909 & 0.6068 & 0.6187 & 0.6362 & 0.6460 & 0.6513 & 0.6542 & 0.6546 & 0.6557 & 0.6553 & 0.6550 & 0.6546 & 0.6477 & 0.6423 & 0.6402 & 0.6365 & 0.6361 & 0.6315 & 0.6205 & 0.6140 & 0.5928
\end{tabular}

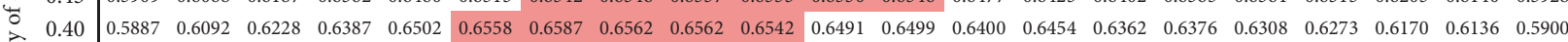

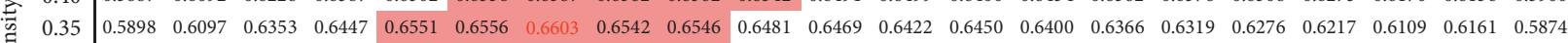

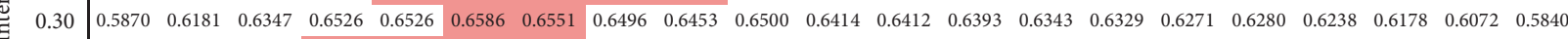
$\begin{array}{lllllllllllllllllllllllll}0.25 & 0.5862 & 0.6191 & 0.6473 & 0.6561 & 0.6562 & 0.6575 & 0.6555 & 0.6489 & 0.6431 & 0.6433 & 0.6383 & 0.6331 & 0.6303 & 0.6331 & 0.6311 & 0.6288 & 0.6269 & 0.6200 & 0.6186 & 0.6084 & 0.5823\end{array}$ $\begin{array}{llllllllllllllllllllllll}0.20 & 0.5902 & 0.6274 & 0.6519 & 0.6573 & 0.6545 & 0.6497 & 0.6457 & 0.6393 & 0.6408 & 0.6395 & 0.6304 & 0.6282 & 0.6266 & 0.6283 & 0.6251 & 0.6247 & 0.6236 & 0.6181 & 0.6137 & 0.6008 & 0.5780\end{array}$ $\begin{array}{lllllllllllllllllllllllll}0.15 & 0.5824 & 0.6308 & 0.6590 & 0.6541 & 0.6523 & 0.6418 & 0.6416 & 0.6363 & 0.6361 & 0.6349 & 0.6305 & 0.6268 & 0.6292 & 0.6298 & 0.6206 & 0.6204 & 0.6226 & 0.6148 & 0.6104 & 0.5988 & 0.5697\end{array}$ $\begin{array}{lllllllllllllllllllllllll}0.10 & 0.5813 & 0.6437 & 0.6514 & 0.6460 & 0.6344 & 0.6330 & 0.6310 & 0.6264 & 0.6277 & 0.6270 & 0.6316 & 0.6264 & 0.6235 & 0.6236 & 0.6211 & 0.6226 & 0.6123 & 0.6088 & 0.5996 & 0.5939 & 0.5634\end{array}$ $\begin{array}{lllllllllllllllllllllll}0.05 & 0.5785 & 0.6454 & 0.6347 & 0.6242 & 0.6227 & 0.6281 & 0.6260 & 0.6295 & 0.6245 & 0.6233 & 0.6231 & 0.6217 & 0.6114 & 0.6098 & 0.6083 & 0.6015 & 0.5976 & 0.5944 & 0.5849 & 0.5747 & 0.5562\end{array}$

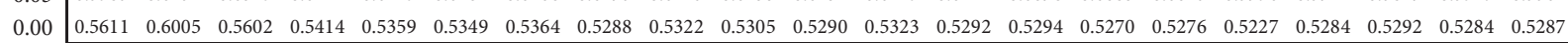
$\begin{array}{lllllllllllllllllllll}0.00 & 0.05 & 0.10 & 0.15 & 0.20 & 0.25 & 0.30 & 0.35 & 0.40 & 0.45 & 0.50 & 0.55 & 0.60 & 0.65 & 0.70 & 0.75 & 0.80 & 0.85 & 0.90 & 0.95 & 1.00\end{array}$ Intensity of exploitative practice
\end{abstract}

(a)

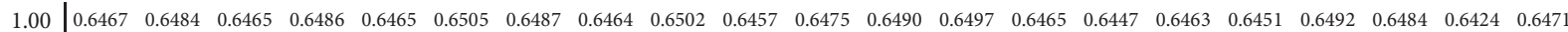
$\begin{array}{lllllllllllllllllllllllllll}0.95 & 0.6463 & 0.6452 & 0.6492 & 0.6488 & 0.6507 & 0.6494 & 0.6548 & 0.6575 & 0.6604 & 0.6660 & 0.6691 & 0.6657 & 0.6719 & 0.6774 & 0.6852 & 0.6871 & 0.6931 & 0.6932 & 0.6913 & 0.6861 & 0.6504\end{array}$ $\begin{array}{lllllllllllllllllllllll}0.90 & 0.6445 & 0.6452 & 0.6478 & 0.6533 & 0.6541 & 0.6606 & 0.6596 & 0.6646 & 0.6717 & 0.6726 & 0.6818 & 0.6912 & 0.6967 & 0.7048 & 0.7084 & 0.7143 & 0.7231 & 0.7292 & 0.7245 & 0.7167 & 0.6501\end{array}$ $\begin{array}{lllllllllllllllllllllllll}0.85 & 0.6459 & 0.6502 & 0.6534 & 0.6548 & 0.6593 & 0.6636 & 0.6725 & 0.6770 & 0.6836 & 0.6897 & 0.6956 & 0.7011 & 0.7152 & 0.7216 & 0.7294 & 0.7401 & 0.7464 & 0.7475 & 0.7476 & 0.7304 & 0.6444\end{array}$ $\begin{array}{llllllllllllllllllllllllll}0.80 & 0.6422 & 0.6503 & 0.6502 & 0.6577 & 0.6651 & 0.6713 & 0.6761 & 0.6879 & 0.6934 & 0.7073 & 0.7078 & 0.7219 & 0.7302 & 0.7435 & 0.7501 & 0.7567 & 0.7628 & 0.7659 & 0.7638 & 0.7529 & 0.6452\end{array}$ $\begin{array}{lllllllllllllllllllllll}0.75 & 0.6446 & 0.6495 & 0.6518 & 0.6600 & 0.6685 & 0.6763 & 0.6843 & 0.6947 & 0.7046 & 0.7114 & 0.7272 & 0.7339 & 0.7421 & 0.7540 & 0.7579 & 0.7678 & 0.7726 & 0.7775 & 0.7741 & 0.7547 & 0.6428\end{array}$ $\begin{array}{llllllllllllllllllllllllll}\mathscr{\Xi} & 0.70 & 0.6433 & 0.6481 & 0.6581 & 0.6664 & 0.6726 & 0.6846 & 0.6954 & 0.7018 & 0.7137 & 0.7226 & 0.7355 & 0.7465 & 0.7544 & 0.7651 & 0.7729 & 0.7726 & 0.7821 & 0.7832 & 0.7822 & 0.7620 & 0.6422\end{array}$ $\begin{array}{lllllllllllllllllllllll} & 0.65 & 0.6407 & 0.6449 & 0.6602 & 0.6668 & 0.6767 & 0.6906 & 0.7036 & 0.7146 & 0.7256 & 0.7348 & 0.7479 & 0.7554 & 0.7662 & 0.7733 & 0.7798 & 0.7858 & 0.7883 & 0.7883 & 0.7902 & 0.7704 & 0.6385\end{array}$ $\begin{array}{lllllllllllllllllllllllll} & 0.60 & 0.6406 & 0.6499 & 0.6634 & 0.6739 & 0.6843 & 0.7004 & 0.7103 & 0.7215 & 0.7359 & 0.7481 & 0.7560 & 0.7636 & 0.7779 & 0.7804 & 0.7868 & 0.7893 & 0.7949 & 0.7960 & 0.7866 & 0.7724 & 0.6358\end{array}$ $\begin{array}{llllllllllllllllllllllllll}\text { 总 } & 0.55 & 0.6426 & 0.6509 & 0.6626 & 0.6760 & 0.6933 & 0.7065 & 0.7221 & 0.7354 & 0.7432 & 0.7602 & 0.7705 & 0.7767 & 0.7808 & 0.7868 & 0.7939 & 0.7953 & 0.7981 & 0.8015 & 0.7919 & 0.7694 & 0.6358\end{array}$ \begin{tabular}{llllllllllllllllllllllllll}
\hline & 0.50 & 0.6403 & 0.6508 & 0.6674 & 0.6826 & 0.6982 & 0.7149 & 0.7318 & 0.7449 & 0.7595 & 0.7693 & 0.7766 & 0.7838 & 0.7880 & 0.7973 & 0.7982 & 0.8006 & 0.8043 & 0.8000 & 0.7934 & 0.7745 & 0.6356
\end{tabular} \begin{tabular}{ll|llllllllllllllllllllllll} 
突 & 0.45 & 0.6354 & 0.6508 & 0.6729 & 0.6886 & 0.7092 & 0.7237 & 0.7450 & 0.7581 & 0.7693 & 0.7780 & 0.7842 & 0.7916 & 0.7955 & 0.8022 & 0.8037 & 0.8025 & 0.8060 & 0.8012 & 0.7887 & 0.7731 & 0.6323
\end{tabular} $\begin{array}{lllllllllllllllllllllll}0.6346 & 0.6523 & 0.6741 & 0.6946 & 0.7184 & 0.7420 & 0.7524 & 0.7633 & 0.7742 & 0.7876 & 0.7933 & 0.7923 & 0.7992 & 0.8032 & 0.8047 & 0.8035 & 0.8037 & 0.8001 & 0.7950 & 0.7732 & 0.6286 & 0.75\end{array}$ $\begin{array}{llllllllllllllllllllll}0.6363 & 0.6552 & 0.6827 & 0.7078 & 0.7290 & 0.7447 & 0.7640 & 0.7729 & 0.7849 & 0.7903 & 0.7973 & 0.8035 & 0.8057 & 0.8054 & 0.8027 & 0.8048 & 0.8008 & 0.7933 & 0.7934 & 0.7712 & 0.6276\end{array}$ $\begin{array}{llllllllllllllllllllllll}0.6300 & 0.6586 & 0.6874 & 0.7149 & 0.7375 & 0.7574 & 0.7720 & 0.7844 & 0.7887 & 0.7994 & 0.8009 & 0.8039 & 0.8045 & 0.8074 & 0.8029 & 0.8061 & 0.7988 & 0.7976 & 0.7909 & 0.7613 & 0.6224\end{array}$ $\begin{array}{llllllllllllllllllllllll}0.25 & 0.6297 & 0.6610 & 0.6992 & 0.7286 & 0.7529 & 0.7711 & 0.7827 & 0.7910 & 0.7937 & 0.7983 & 0.8056 & 0.8030 & 0.8042 & 0.8081 & 0.8037 & 0.7965 & 0.7965 & 0.7943 & 0.7834 & 0.7561 & 0.6174\end{array}$ \begin{tabular}{l|llllllllllllllllllllllll}
0.20 & 0.6271 & 0.6742 & 0.7098 & 0.7430 & 0.7594 & 0.7794 & 0.7859 & 0.7957 & 0.7975 & 0.8003 & 0.8068 & 0.8023 & 0.8059 & 0.8009 & 0.7949 & 0.7940 & 0.7919 & 0.7837 & 0.7742 & 0.7486 & 0.6103
\end{tabular} $\begin{array}{llllllllllllllllllllllllll}0.15 & 0.6207 & 0.6773 & 0.7279 & 0.7481 & 0.7725 & 0.7830 & 0.7867 & 0.7954 & 0.7947 & 0.8011 & 0.7991 & 0.7947 & 0.7967 & 0.7928 & 0.7856 & 0.7829 & 0.7761 & 0.7729 & 0.7575 & 0.7342 & 0.6077\end{array}$ \begin{tabular}{l|lllllllllllllllllllllll}
0.10 & 0.6203 & 0.6920 & 0.7363 & 0.7591 & 0.7736 & 0.7849 & 0.7849 & 0.7868 & 0.7864 & 0.7876 & 0.7817 & 0.7779 & 0.7790 & 0.7767 & 0.7714 & 0.7667 & 0.7577 & 0.7518 & 0.7330 & 0.7076 & 0.6036
\end{tabular} $\begin{array}{lllllllllllllllllllllllllll}0.05 & 0.6140 & 0.7145 & 0.7475 & 0.7542 & 0.7625 & 0.7670 & 0.7651 & 0.7654 & 0.7600 & 0.7593 & 0.7506 & 0.7499 & 0.7400 & 0.7384 & 0.7355 & 0.7289 & 0.7153 & 0.7108 & 0.6929 & 0.6614 & 0.5847\end{array}$ \begin{tabular}{l|llllllllllllllllllllllllll}
0.00 & 0.5983 & 0.6692 & 0.5973 & 0.5761 & 0.5595 & 0.5464 & 0.5432 & 0.5415 & 0.5409 & 0.5354 & 0.5413 & 0.5304 & 0.5368 & 0.5288 & 0.5333 & 0.5315 & 0.5262 & 0.5256 & 0.5291 & 0.5290 & 0.5296 \\
\hline
\end{tabular} $\begin{array}{lllllllllllllllllllll}0.00 & 0.05 & 0.10 & 0.15 & 0.20 & 0.25 & 0.30 & 0.35 & 0.40 & 0.45 & 0.50 & 0.55 & 0.60 & 0.65 & 0.70 & 0.75 & 0.80 & 0.85 & 0.90 & 0.95 & 1.00\end{array}$ Intensity of exploitative practice

(b)

FiguRE 5: Continued. 


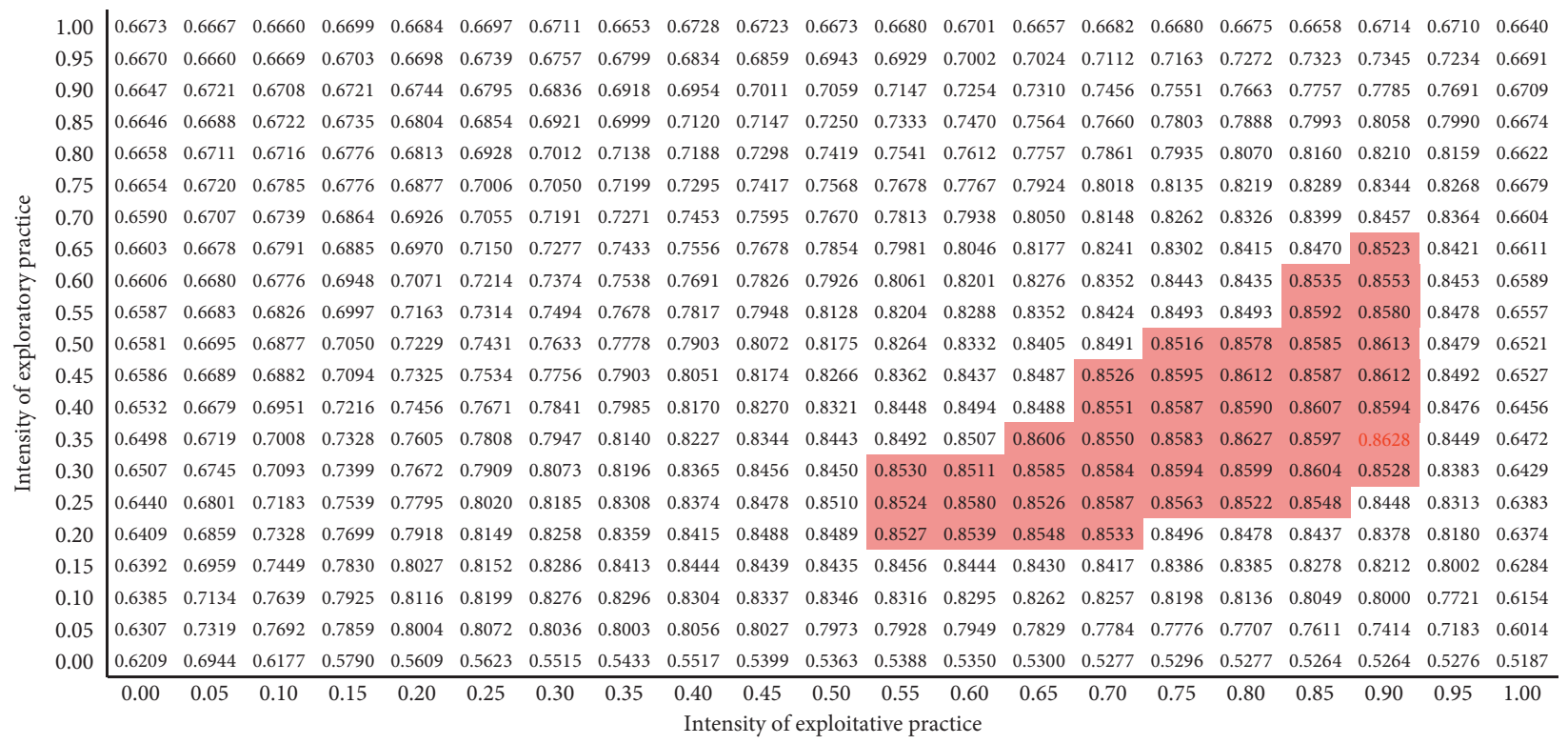

(c)

FIGURE 5: Effect of absorptive capacity on organizational adaptability and practice strategy. (a) $p_{2}=0.1$. (b) $p_{2}=0.5$. (c) $p_{2}=0.9$.

knowledge with time under various absorptive capacities, although the rate of increase gradually diminishes. The more absorbent the organization is for the same amount of time operating, the higher the level of organizational knowledge. The knowledge gap at different levels of absorptive capacity decreases over time.

\section{Discussion}

In this study, we suggest an integrative framework, as shown in Figure 1, where not only are the internal conditions of the organization considered but also the external reality. Utilizing the natural advantages of model simulation, we realized a research design that takes environmental dynamism and organizational absorptive capacity as control variables. This compensates for the shortcomings of empirical studies. Such a research design brings some theoretical and practical insights and also provides directions for further empirical research.

5.1. Theoretical Implications. This paper emphasizes the negative impact of environmental dynamism on organizational adaptability but does not suggest that organizations are powerless against changes in reality, as the population ecology theory [7] would have us believe. Hannan and Freeman [7] point that environmental selection is a major factor in determining the survival of an organization, and thus, it is difficult for an organization to adapt to its environment through learning. The research in this paper offers a different insight into this. Our results show the proactive side of organizational strategy formulation in the interaction with the environment. Environmental dynamism cannot be changed, but adaptive internal arrangements can be made through the reallocation of organizational resources. This supports the view of strategic choice theory [42]. In addition, the positive impact of organizational capability enhancement on organizational adaptability is also confirmed in this paper. Considering that organizational capability is an important basis for organizational strategy formulation, this paper realizes the integration of dynamic capabilities theory and strategic choice theory. Overall, this study acknowledges the interaction and synergistic evolution between environment, capabilities, and strategy, rather than determination. In this dynamic process, organizational learning acts as a bridge from past behavior to future action, which reflects both passive adaptation and positive operation of the organization to the environment.

5.2. Managerial Implications. The results of this paper mitigate the optimism of resisting the erosion of environmental dynamism through exploration. Not only is it important not to increase exploration but also to decrease exploitation. For strategy-makers of companies facing environmental dynamism, shrinking the front is a more appropriate option than blind expansion. China's current real estate industry is a prime example of this. With the frequent promulgation of regulatory policies, real estate companies are facing drastic fluctuations in their survival environment. Most of those companies investing in new tracks are facing the threat of capital chain breakage. On the contrary, those companies that have gained cash flow security by selling some of their assets and reducing land acquisitions are still operating smoothly, albeit with much worse performance than before. In addition, considering the positive impact of organizational absorptive capacity on adaptability, managers should pay attention to continuous learning and capacity enhancement of members, because individual absorptive capacity is the basis of an organization. Direct recruitment of 
TABLE 1: Regression results.

\begin{tabular}{|c|c|c|c|c|c|c|c|c|}
\hline \multirow{2}{*}{ Variable } & \multicolumn{4}{|c|}{ Model 1} & \multicolumn{4}{|c|}{ Model 2} \\
\hline & $B$ & $\beta$ & $t$ & VIF & $B$ & $\beta$ & $t$ & VIF \\
\hline IIP & $0.072^{* * *}$ & $0.211^{* * *}$ & 15.790 & 1.000 & $0.072^{* * *}$ & $0.211^{* * *}$ & 16.270 & 1.000 \\
\hline IRP & $-0.043^{* * *}$ & $-0.127^{* * *}$ & -9.491 & 1.000 & $-0.043^{* * *}$ & $-0.127^{* * *}$ & -9.779 & 1.000 \\
\hline ED & $-9.516^{* * *}$ & $-0.519^{* * *}$ & -38.782 & 1.000 & $-9.516^{* * *}$ & $-0.519^{* * *}$ & -39.960 & 1.000 \\
\hline $\mathrm{AC}$ & $0.165^{* * *}$ & $0.343^{* * *}$ & 25.606 & 1.000 & $0.165^{* * *}$ & $0.343^{* * *}$ & 26.384 & 1.000 \\
\hline $\mathrm{IIP} * \mathrm{ED}$ & & & & & $-6.909^{* * *}$ & $-0.114^{* * *}$ & -8.783 & 1.000 \\
\hline $\mathrm{IIP} * \mathrm{AC}$ & & & & & $0.126^{* * *}$ & $0.079^{* * *}$ & 6.113 & 1.000 \\
\hline $\mathrm{IRP} * \mathrm{ED}$ & & & & & $6.495^{* * *}$ & $0.107^{* * *}$ & 8.257 & 1.000 \\
\hline $\mathrm{IRP} * \mathrm{AC}$ & & & & & $-0.070^{* * *}$ & $-0.044^{* * *}$ & -3.378 & 1.000 \\
\hline$\Delta \mathrm{f}$ & \multicolumn{4}{|c|}{$624.777^{* * *}$} & \multicolumn{4}{|c|}{$48.524^{* * *}$} \\
\hline$R^{2}$ & \multirow{2}{*}{\multicolumn{4}{|c|}{$0.448^{* * *}$}} & \multicolumn{4}{|c|}{$0.481^{* * *}$} \\
\hline$\Delta \mathrm{R}^{2}$ & & & & & \multicolumn{4}{|c|}{$0.033^{* * *}$} \\
\hline
\end{tabular}

IIP: intensity of exploitative practice; IRP: intensity of exploratory practice; ED: environmental dynamism; AC: absorptive capacity; B: unstandardized estimate; $\beta$ : standardized estimate; VIF: variance inflation factor. Significance: ${ }^{* * *} p<0.001$ (two-tailed). Sample size: 3087.

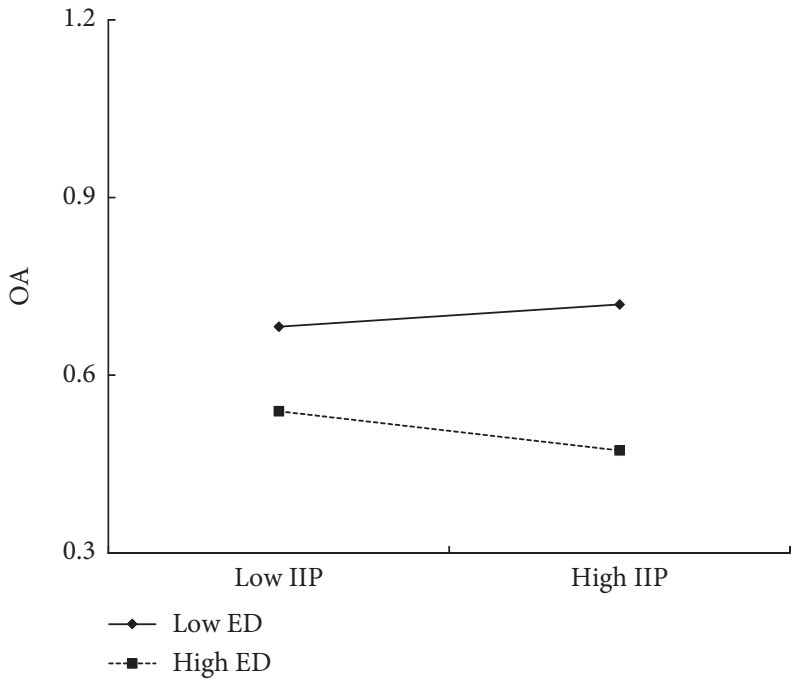

(a)

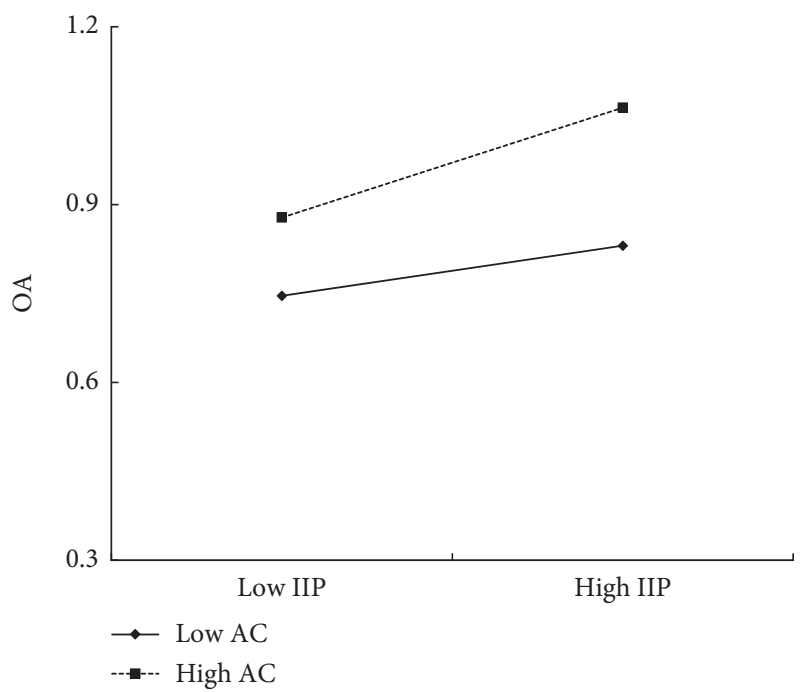

(c)

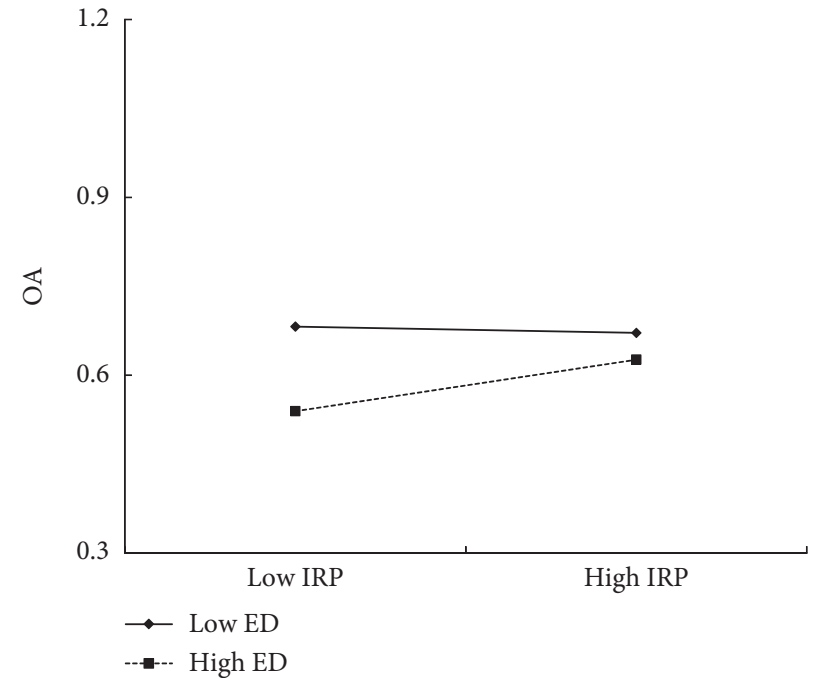

(b)

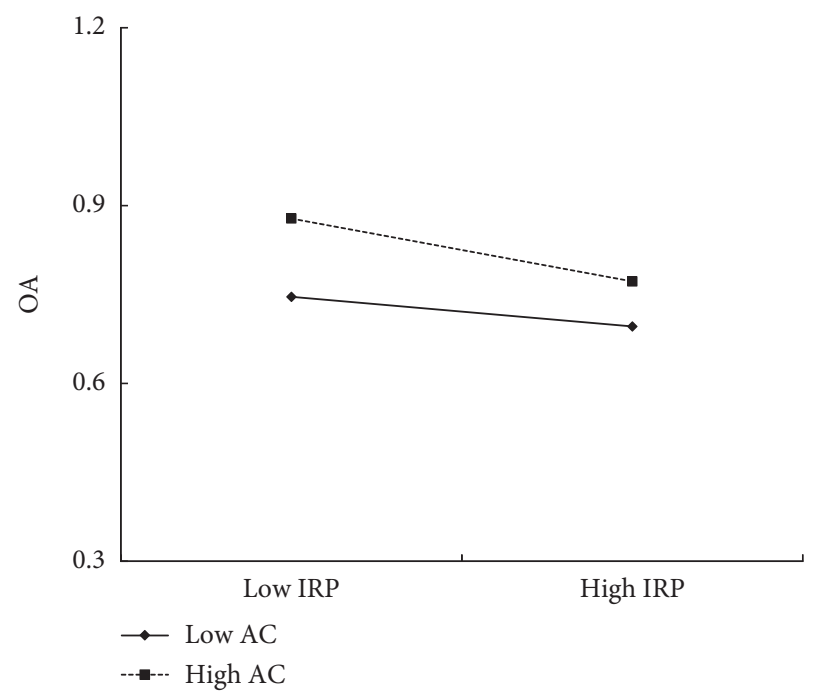

(d)

Figure 6: Moderating effects. (a) H3a; (b) H3b; (c) H4a; (d) H4b. 
TABLe 2: Results of testing simple slopes.

\begin{tabular}{|c|c|c|c|c|}
\hline Level of predictor & Level of moderator & Gradient & $t$ & Sig. \\
\hline \multirow{4}{*}{ IIP } & Low ED & 0.037 & 6.289 & 0.000 \\
\hline & High ED & -0.066 & -4.046 & 0.000 \\
\hline & Low AC & 0.085 & 18.917 & 0.000 \\
\hline & High AC & 0.185 & 41.457 & 0.000 \\
\hline \multirow{4}{*}{ IRP } & Low ED & -0.011 & -1.767 & 0.077 \\
\hline & High ED & 0.087 & 5.313 & 0.000 \\
\hline & Low AC & -0.05 & -11.18 & 0.000 \\
\hline & High AC & -0.106 & -23.702 & 0.000 \\
\hline
\end{tabular}

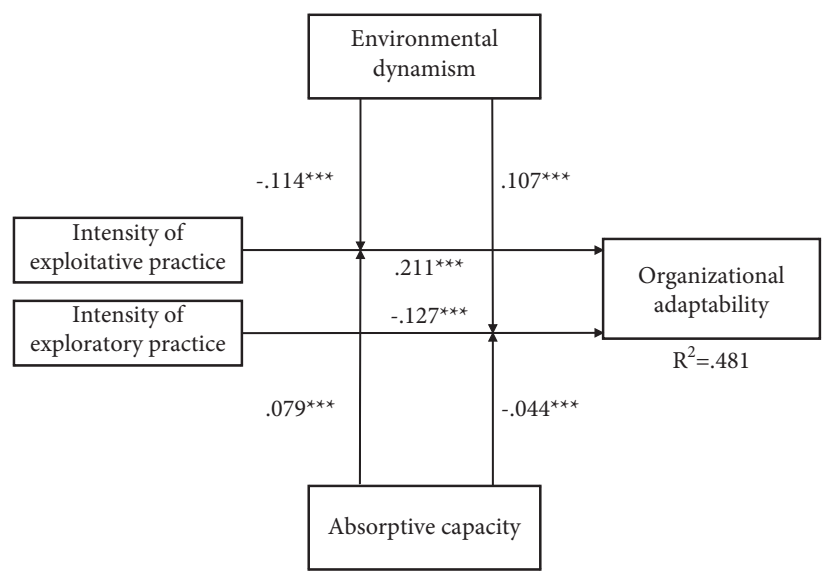

FIgURE 7: Result of MRA for the research model.

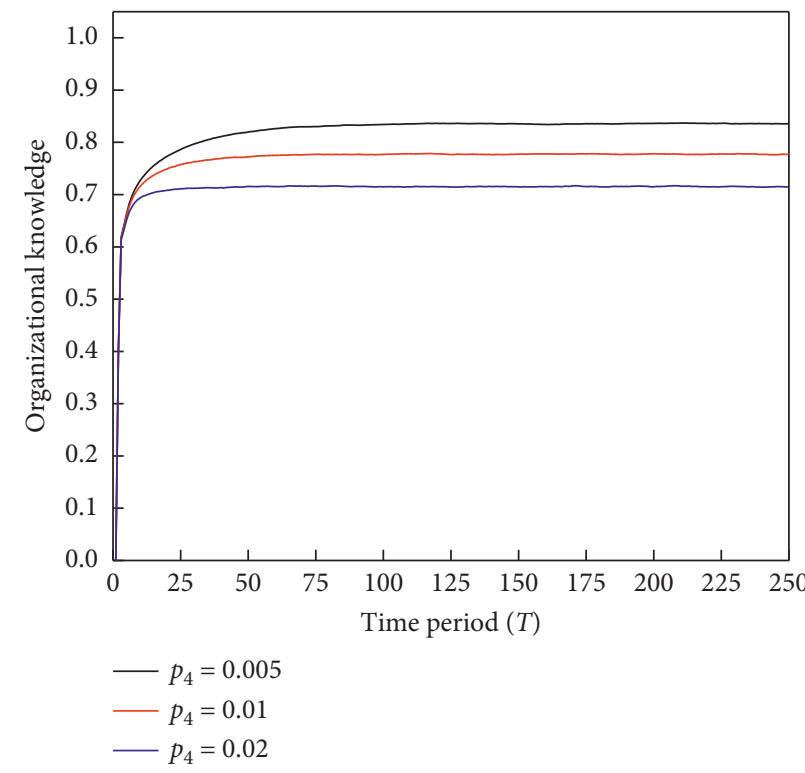

(a)

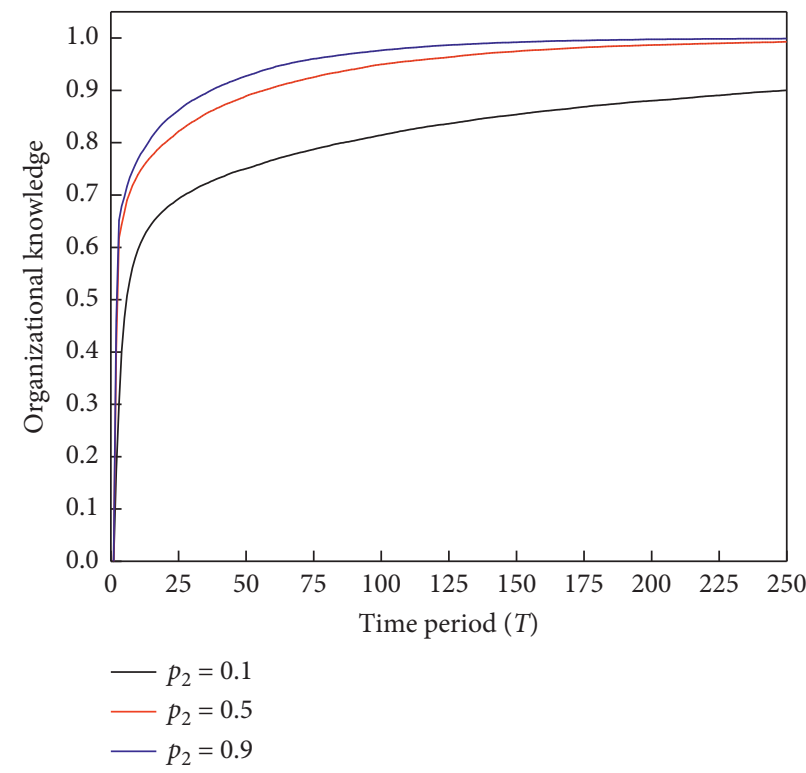

(b)

FIGURE 8: Effect of practice time on organizational knowledge. (a) Environmental dynamism $\left(p_{1}=0.5, p_{2}=0.5, p_{3}=0.5\right)$. (b) Organizational absorptive capacity $\left(p_{1}=0.5, p_{3}=0.5, p_{4}=0\right)$.

elite individuals who are good at knowledge integration and development is a quick way. But what is more important is to reduce the cost of knowledge acquisition, create an atmosphere that encourages learning, and establish reward mechanisms for knowledge contribution. These intrinsic motivations are more conducive to sustainable organizational development but require a lot of effort and enough patience on the part of managers. 
5.3. Limitations and Future Research. This article is based entirely on March's formal model without considering additional extensions, such as frequency and amplitude of environmental dynamism [3], tacit knowledge [37], individual experimentation [22], interpersonal learning [3,37], and organizational forgetting [43]. Whether and to what extent these real-world features have an impact on the conclusions of this work is a direction worthy of continued indepth study. In addition, this paper investigates the impact of different practice strategies on organizational adaptability. The design and implementation of practice strategies require the support of organizational resources. This study does not take into account the limited organizational resources and the different costs of exploratory versus exploitative practices. How to maximize organizational performance by appropriately allocating valuable resources to different types of practices can be an important issue for future empirical research. Another related question is that real organizations may be more concerned with cost performance, i.e., inputoutput ratio, rather than the maximum value in the ideal state.

\section{Conclusion}

In this study, we first revisit and accurately reconstruct March's classical simulation model. Then, we undertake our investigation based on this formal model of high standing. Specifically, we have examined the effects of practice strategy, environmental dynamism, and absorptive capacity on organizational adaptability to the environment. The conclusions of the research are shown as follows:

(1) In a stable environment, the intensity of developmental practices has a significant positive effect on organizational adaptability, while the intensity of exploratory practices has a significant negative effect

(2) Environmental dynamism significantly weakens the relationship between the intensity of exploitative practice, as well as exploratory practice, and organizational adaptability

(3) Organizational absorptive capacity has a significant strengthening effect on the association between the intensity of exploitative practice and organizational adaptability and that between the intensity of exploratory practice and organizational adaptability

\section{Data Availability}

The program details and data used to support the findings of this study are available from the corresponding author upon request.

\section{Conflicts of Interest}

The authors declare that there are no conflicts of interest regarding the publication of this study.

\section{Acknowledgments}

This research was funded by the National Natural Science Foundation of China (71871164).

\section{References}

[1] C.-A. Chen, "Revisiting organizational age, inertia, and adaptability developing and testing a multi-stage model in the nonprofit sector," Journal of Organizational Change Management, vol. 27, no. 2, pp. 251-272, 2014.

[2] R.-G. C. Dirksen, "Organizational development through brand strategy the origin in practice," Gio-Gruppe-Interaktion-Organisation-Zeitschrift Fuer Angewandte Organisationspsychologie, vol. 52, no. 3, pp. 525-536, 2021.

[3] T. Kim and M. Rhee, "Exploration and exploitation: internal variety and environmental dynamism," Strategic Organization, vol. 7, no. 1, pp. 11-41, 2009.

[4] K. N. M. Dundas and P. R. Richardson, "Corporate strategy and the concept of market failure," Strategic Management Journal, vol. 1, no. 2, pp. 177-188, 1980.

[5] H. I. Ansoff, "Strategic issue management," Strategic Management Journal, vol. 1, no. 2, pp. 131-148, 1980.

[6] M. E. Porter, "Clusters and the new economics of competition,” Harvard Business Review, vol. 76, no. 6, pp. 77-90, 1998.

[7] T. H. Michael and F. John, "The population ecology of organizations," American Journal of Sociology, vol. 82, no. 5, pp. 929-964, 1977.

[8] F. Luthans, "The contingency theory of management. A path out of the jungle," Business Horizons, vol. 16, no. 3, pp. 67-72, 1973.

[9] P. J. Dimaggio and W. W. Powell, "The iron cage revisited institutional isomorphism and collective rationality IN organizational fields," American Sociological Review, vol. 48, no. 2, pp. 147-160, 1983.

[10] A. Y. Lewin and H. W. Volberda, "Prolegomena on coevolution: a framework for research on strategy and new organizational forms," Organization Science, vol. 10, no. 5, pp. 519-534, 1999.

[11] J. Barney, M. Wright, and D. J. Ketchen, “The resource-based view of the firm: ten years after 1991," Journal of Management, vol. 27, no. 6, pp. 625-641, 2001.

[12] K. M. B. Gravenhorst, R. A. Werkman, and J. J. Boonstra, "The change capacity of organisations: general assessment and five configurations," Applied Psychology-an International ReviewPsychologie Appliquee-Revue Internationale, vol. 52, no. 1, pp. 83-105, 2003.

[13] D. J. Teece, G. Pisano, and A. Shuen, "Dynamic capabilities and strategic management," Strategic Management Journal, vol. 18, no. 7, pp. 509-533, 1997.

[14] X. A. F. Chaparro, R. Kozesinski, and A. S. C. Júnior, "Absorptive capacity in startups: a systematic literature review," Journal of Entrepreneurship, Management and Innovation, vol. 17, no. 1, pp. 57-95, 2021.

[15] R. E. Ployhart and T. P. Moliterno, "Emergence OF the human capital resource: a multilevel model," Academy of Management Review, vol. 36, no. 1, pp. 127-150, 2011.

[16] R. G. Rocha and P. G. Pinheiro, "Organizational spirituality and knowledge management supporting organizational practical wisdom," Spirituality Studies, vol. 7, no. 1, pp. 68-83, 2021.

[17] S. S. Chanda, "Inferring final organizational outcomes from intermediate outcomes of exploration and exploitation: the complexity link," Computational \& Mathematical Organization Theory, vol. 23, no. 1, pp. 61-93, 2017.

[18] A. D. Chandler, "Corporate strategy and structure: some current considerations," Society, vol. 28, no. 3, pp. 35-38, 1991. 
[19] W. G. Bennis, "Organizational developments and the fact of bureaucracy," Industrial Management Review, vol. 7, pp. 41$55,1966$.

[20] S. Chowdhury, "The role of affect- and cognition-based trust in complex knowledge sharing," Journal of Managerial Issues, vol. 17, no. 3, pp. 310-326, 2005.

[21] Y. Peng and S. T. Liu, "Complex adaptive organization change: an empirical study on Chinese telecom enterprise," in Proceedings of the International Conference on Advanced Measurement and Test (AMT 2010) Sanya, China: Trans Tech Publications Ltd, May 2010.

[22] S. Rodan, "Exploration and exploitation revisited: extending March's model of mutual learning," Scandinavian Journal of Management, vol. 21, no. 4, pp. 407-428, 2005.

[23] Y. Peng, J. L. Hou, and J. Wang, "Research on the complex adaptive model of learning organizational change," in Proceedings of the International Conference on Components, Packaging and Manufacturing Technology, Trans Tech Publications Ltd, Sanya, China, January 2010.

[24] G. Yukl and R. Lepsinger, "Why integrating the leading and managing roles is essential for organizational effectiveness," Organizational Dynamics, vol. 34, no. 4, pp. 361-375, 2005.

[25] I. Nonaka, "The knowledge-creating company," Harvard Business Review, vol. 85, no. 7-8, p. 162, 2007.

[26] X. Zhang, Y. Le, Y. Liu, and X. Chen, "Fostering ambidextrous innovation strategies in large infrastructure projects: a team heterogeneity perspective," IEEE Transactions on Engineering Management, 2021.

[27] X. Zhang, Y. Le, Y. Liu, and M. Liu, "Fostering ambidextrous innovation in infrastructure projects: differentiation and integration tactics of cross-functional teams," Journal of Construction Engineering and Management, vol. 147, no. 6, Article ID 04021046, 2021.

[28] S. S. Chanda and B. McKelvey, "Back to the basics: reconciling the continuum and orthogonal conceptions of exploration and exploitation," Computational \& Mathematical Organization Theory, vol. 26, no. 2, pp. 175-206, 2020.

[29] G. G. Dess and D. W. Beard, "Dimensions OF organizational task environments," Administrative Science Quarterly, vol. 29, no. 1, pp. 52-73, 1984.

[30] W. M. Cohen and D. A. Levinthal, "Absorptive-capacity - a new perspective on learning and innovation," Administrative Science Quarterly, vol. 35, no. 1, pp. 128-152, 1990.

[31] G. Todorova and B. Durisin, "Absorptive capacity: valuing a reconceptualization," Academy of Management Review, vol. 32, no. 3, pp. 774-786, 2007.

[32] P. Y. T. Sun and M. H. Anderson, "An examination of the relationship between absorptive capacity and organizational learning, and a proposed integration," International Journal of Management Reviews, vol. 12, no. 2, pp. 130-150, 2010.

[33] K. D. Miller, "Agent-based modeling and organization studies: a critical realist perspective," Organization Studies, vol. 36, no. 2, pp. 175-196, 2015.

[34] J. B. Vancouver and J. M. Weinhardt, "Modeling the mind and the milieu: computational modeling for micro-level organizational researchers," Organizational Research Methods, vol. 15, no. 4, pp. 602-623, 2012.

[35] S. S. Chanda, S. Ray, and B. McKelvey, "The continuum conception of exploration and exploitation: an update to March's theory," Management, vol. 21, no. 3, pp. 1032-1079, 2018.

[36] J. G. March, "Exploration and exploitation in organizational learning," Organization Science, vol. 2, no. 1, pp. 71-87, 1991.
[37] K. D. Miller, M. Zhao, and R. J. Calantone, "Adding interpersonal learning and tacit knowledge to March's explorationexploitation model," Academy of Management Journal, vol. 49, no. 4, pp. 709-722, 2006.

[38] S. S. Chanda and S. Ray, "Optimal exploration and exploitation: the managerial intentionality perspective," Computational \& Mathematical Organization Theory, vol. 21, no. 3, pp. 247-273, 2015.

[39] S. S. Chanda and K. D. Miller, "Replicating agent-based models: revisiting March's exploration-exploitation study," Strategic Organization, vol. 17, no. 4, pp. 425-449, 2019.

[40] H. A. Simon, "Rational choice and the structure of the environment," Psychological Review, vol. 63, no. 2, pp. 129-138, 1956.

[41] J. F. Dawson, "Moderation in management research: what, why, when, and how," Journal of Business and Psychology, vol. 29, no. 1, pp. 1-19, 2014.

[42] J. Child, "Organizational structure, environment and performance: the role of strategic choice," Sociology, vol. 6, no. 1, pp. 1-22, 1972.

[43] K. D. Miller and D. Martignoni, “Organizational learning with forgetting: reconsidering the exploration-exploitation tradeoff," Strategic Organization, vol. 14, no. 1, pp. 53-72, 2016. 